OPEN ACCESS

Edited by:

Xiaolin Zhou,

Peking University, China

Reviewed by:

Rik Vandenberghe,

KU Leuven, Belgium

Qiu Jiang,

Southwest Normal University China,

China

*Correspondence:

C. S. E. Weston

weston_charles@hotmail.com

Received: 07 March 2018 Accepted: 02 August 2018 Published: 22 August 2018

Citation:

Weston CSE (2018) Amygdala Represents Diverse Forms of Intangible Knowledge, That Illuminate

Social Processing and Major Clinical Disorders.

Front. Hum. Neurosci. 12:336. doi: 10.3389/fnhum.2018.00336

\section{Amygdala Represents Diverse Forms of Intangible Knowledge, That Illuminate Social Processing and Major Clinical Disorders}

\section{S. E. Weston*}

Independent Researcher, Amboise, France

Amygdala is an intensively researched brain structure involved in social processing and multiple major clinical disorders, but its functions are not well understood. The functions of a brain structure are best hypothesized on the basis of neuroanatomical connectivity findings, and of behavioral, neuroimaging, neuropsychological and physiological findings. Among the heaviest neuroanatomical interconnections of amygdala are those with perirhinal cortex (PRC), but these are little considered in the theoretical literature. PRC integrates complex, multimodal, meaningful and fine-grained distributed representations of objects and conspecifics. Consistent with this connectivity, amygdala is hypothesized to contribute meaningful and fine-grained representations of intangible knowledge for integration by PRC. Behavioral, neuroimaging, neuropsychological and physiological findings further support amygdala mediation of a diversity of such representations. These representations include subjective valence, impact, economic value, noxiousness, importance, ingroup membership, social status, popularity, trustworthiness and moral features. Further, the formation of amygdala representations is little understood, and is proposed to be often implemented through embodied cognition mechanisms. The hypothesis builds on earlier work, and makes multiple novel contributions to the literature. It highlights intangible knowledge, which is an influential but insufficiently researched factor in social and other behaviors. It contributes to understanding the heavy but neglected amygdala-PRC interconnections, and the diversity of amygdala-mediated intangible knowledge representations. Amygdala is a social brain region, but it does not represent species-typical social behaviors. A novel proposal to clarify its role is postulated. The hypothesis is also suggested to illuminate amygdala's involvement in several core symptoms of autism spectrum disorder (ASD). Specifically, novel and testable explanations are proposed for the ASD symptoms of disorganized visual scanpaths, apparent social disinterest, preference for concrete cognition, aspects of the disorder's heterogeneity, and impairment in some activities of daily living. Together, the presented hypothesis demonstrates substantial explanatory potential in the neuroscience, social and clinical domains.

Keywords: amygdala, perirhinal cortex, intangible knowledge, embodied cognition, paradoxical functional facilitation, autism spectrum disorder 


\section{INTRODUCTION}

Amygdala is a complex brain structure, that is located in medial temporal lobe, and comprises some 13 nuclei and cortical areas in monkey (Freese and Amaral, 2009). Major nuclei are the lateral, basal, accessory basal and central amygdaloid nuclei, which constitute $33 \%, 27 \%, 10 \%$ and $3 \%$ of total amygdaloid neuron numbers in human, respectively (Schumann and Amaral, 2005). Amygdala is an ancient structure, with a homolog of it present in reptiles and origins in still earlier animal groups (Laberge et al., 2006; Murray et al., 2009), as well as exceptionally widely interconnected in primate (Young et al., 1994; Freese and Amaral, 2009). Amygdala is also a multi-functional brain region, with some functions being well established, such as emotional memory enhancement (Hamann, 2009; Murty et al., 2010; McIntyre et al., 2012; McGaugh, 2013), and participation in the fear network (Shin and Liberzon, 2010; LeDoux, 2014; Janak and Tye, 2015). Other functions are more recently reported, as with the representation of features of behavioral plans (Hernádi et al., 2015; Zangemeister et al., 2016).

Amygdala is likely involved in further cognitive functions, and has long been suggested to mediate importance, significance, salience and so forth (Geschwind, 1965; Gloor et al., 1982; Amaral and Price, 1984; Sander et al., 2003; LaBar and Warren, 2009; Phelps, 2009; Adolphs, 2010; Pessoa and Adolphs, 2010). These proposals are built upon but reconceptualized and elaborated further in this hypothesis article. Specifically, rather than few, coarse-grained, often genetically pre-specified representations of salience, relevance, or related concepts, the novel hypothesis is presented that a principal function of amygdala is the representation of diverse, meaningful and fine-grained, intangible knowledge representations. Moreover, amygdala often elaborates such knowledge representations through interactions between brain, body and environment, in accordance with the postulates of embodied cognition (Varela et al., 1991; Chiel and Beer, 1997; Clark, 1999, 2008). The hypothesis should significantly advance understanding of amygdala, its involvement in normal social functions, its contribution to clinical disorders with amygdala involvement, such as posttraumatic stress disorder, anxiety disorders, depressive disorders and autism spectrum disorder (ASD; Koenigs et al., 2008; Mayberg, 2009; Schumann and Amaral, 2009; Shin and Liberzon, 2010; Amaral et al., 2011; Price and Drevets, 2012; Weston, 2014), and is relevant for a comprehensive account of amygdala function. Generally, the functions of brain structures are best understood through connectivity findings, and through behavioral, physiological and related findings (Behrens and Johansen-Berg, 2005; Passingham and Wise, 2012), so such findings pertaining to amygdala and related regions will be examined in the next two sections, respectively.

\section{CONNECTIVITY}

\section{Amygdala Connectivity}

Connectivity is largely elucidated through neuroanatomical tracing studies in monkey and rodent, as well as physiological studies. Amygdala interconnections are broadly similar in rodent and non-human primate, and likely in human also (McDonald, 1998). Amygdala receives important inputs from the great majority of sensory modalities, and these relay via high-level subregions of sensory processing pathways. Visual inputs from the anterior-most part of the ventral visual object pathway, principally area TEa in ventral temporal cortex (VTC) in monkey, relay to amygdala (Iwai and Yukie, 1987; McDonald, 1998; Stefanacci and Amaral, 2000, 2002; Freese and Amaral, 2009). Biological motion and multimodal information are processed in superior temporal sulcus (STS; Beauchamp, 2005; Pelphrey et al., 2005; Saygin, 2007), of which predominantly anterior STS relays to amygdala (McDonald, 1998; Stefanacci and Amaral, 2000, 2002; Freese and Amaral, 2009). These interconnections are further supported by findings that early amygdala lesions in monkey and human result in significant degradation of anterior subregions of VTC and STS (Boes et al., 2012; Grayson et al., 2017). Auditory inputs from the high-level auditory area, in monkey predominantly area TAa located in superior temporal gyrus (STG), relay to amygdala (McDonald, 1998; Stefanacci and Amaral, 2000, 2002; Yukie, 2002; Freese and Amaral, 2009). Olfactory information is gathered by sensory cells of the olfactory epithelium, and projected to the olfactory bulb, primary olfactory cortex, thence to secondary olfactory cortex in orbitofrontal cortex (OFC; Shepherd, 2006; Patin and Pause, 2015). The olfactory bulb and olfactory cortices project to several amygdaloid nuclei (McDonald, 1998; Pitkänen, 2000; Patin and Pause, 2015). Further, neuroimaging studies of healthy humans have found reliable amygdala involvement in odor processing (see for review, Patin and Pause, 2015).

Somatosensory, gustatory, nociceptive and viscerosensory information are collected by specialized receptors and processed through multiple and complex sensory processing pathways that include subregions of insula (Friedman et al., 1986; Ostrowsky et al., 2000; Saper, 2000, 2002; Craig, 2002; Gauriau and Bernard, 2002; Pritchard and Norgren, 2004; Mazzola et al., 2006; Small, 2010). Somatosensory information relays from posterior insula to amygdala (Friedman et al., 1986; McDonald, 1998; Pitkänen, 2000), and multiple forms of somatosensation are thereby relayed to amygdala. These include, as found by single-cell recording in monkey, tactile stimulation of the face, for stimuli in the mouth the features of viscosity, fatty texture, grittiness, irritation (elicited by capsaicin) and temperature (Kadohisa et al., 2005; Mosher et al., 2016), and as found by fMRI in human, reducing bodily temperature sensations (Oi et al., 2017). Gustatory information relays from anterior insula to amygdala (McDonald, 1998; Pitkänen, 2000), and single-cell recording studies in monkey report gustatory processing in amygdala (Kadohisa et al., 2005). Nociceptive information relays from posterior insula to amygdala (McDonald, 1998; Gauriau and Bernard, 2002). In addition, clinical and experimental neuroimaging studies of nociceptive processing in human, report activation of a network of brain regions that includes amygdala (see for meta-analysis, Simons et al., 2014).

Viscerosensory nerves of the autonomic nervous system (ANS) collect diverse forms of information from widespread bodily systems, including heart, lungs, gut, pelvic organs 
and so forth, and such information is processed through multiple pathways, that include the insula (Loewy, 1990; Saper, 2002). Subregions of insula relay viscerosensory information to amygdala (McDonald, 1998; Pitkänen, 2000). Consistent with this neuroanatomy, in human respiratory challenge activates a network of brain regions that includes amygdala (Brannan et al., 2001; Liotti et al., 2001; Evans et al., 2002; von Leupoldt et al., 2009). In physiological studies with animals, manipulations of blood pressure, and of blood acidity, have been found to modulate amygdala neuronal activity (Knuepfer et al., 1995; Ziemann et al., 2009). The stress hormone epinephrine binds to vagus neurons of the parasympathetic subdivision of ANS, which projects via subcortical and cortical routes to amygdala (Schreurs et al., 1986; Roozendaal et al., 1997; Saper, 2002; McGaugh, 2004, 2013). Another stress hormone, cortisol, binds directly to glucocorticoid receptors on amygdala, predominantly the basal amygdaloid nucleus, and to glucocorticoid receptors on Nucleus of the Solitary Tract (NTS) neurons in brainstem which project to amygdala (Roozendaal et al., 1997; Saper, 2002; McGaugh, 2004, 2013).

Perirhinal cortex (PRC) comprises Brodmann's areas (BAs) 35,36 , and in the temporal pole part of 38 (also named area TG by von Bonin and Bailey, 1947; Suzuki and Amaral, 1994; Davies et al., 2004). Heavy inputs from PRC originate extensively but most densely from polar PRC, and relay extensively to amygdala, most heavily to lateral, basal, and accessory basal nuclei (Stefanacci et al., 1996; Stefanacci and Amaral, 2000). Lateral, basal, accessory basal and periamygdaloid cortex return the heaviest projections, and relay most densely to polar regions of PRC (Amaral and Price, 1984; Stefanacci et al., 1996). Inputs specifically to lateral amygdaloid nucleus in monkey have been traced quantitatively, and the findings were that the heaviest unimodal sensory input is received from high-level visual area TE in VTC. The heaviest input of all to lateral amygdaloid nucleus, at over twice the magnitude of TE input, is received from PRC (Stefanacci and Amaral, 2000). Similarly for reciprocal projections, (Amaral and Price, 1984, p. 492) report that of amygdala projections to temporal and occipital lobes "the heaviest projections are to the temporal pole (especially area TG) and the inferior temporal cortex (especially areas 35, 36)." Furthermore, neonatal amygdala lesions in monkey produced the heaviest brain structural degradation in PRC (Grayson et al., 2017).

Inputs of modest and robust magnitude relay to amygdala from parahippocampal cortex (PHC) and entorhinal cortex (ERC), respectively (Stefanacci et al., 1996; Suzuki, 1996; Stefanacci and Amaral, 2000; Freese and Amaral, 2009), and are reciprocated modestly to PHC and heavily to ERC (Amaral and Price, 1984; Stefanacci et al., 1996). Further, moderate to robust inputs are received by amygdala from OFC and anterior cingulate cortex (ACC), and heavy return projections relay to OFC and ACC (Amaral and Price, 1984; Stefanacci and Amaral, 2002; Freese and Amaral, 2009; Vogt, 2009). Amygdala also receives and relays dense interconnections with BA 45 in ventrolateral prefrontal cortex (VLPFC;
Gerbella et al., 2014). Numerous subcortical projections that are mainly reciprocal also interconnect with amygdala, largely with thalamus, hippocampus, multiple brainstem regions, hypothalamus, striatum and basal forebrain (Davis, 1992; Suzuki, 1996; Pitkänen, 2000; Freese and Amaral, 2009).

Taken together, the great majority of sensory systems project heavily to robustly to amygdala, and their high-level subregions relay most frequently and strongly to lateral, basal and central amygdaloid nuclei; in addition, amygdala returns heavy projections to extensive parts of visual cortex, STS, STG and insula (Amaral and Price, 1984; Yukie, 2002; Freese and Amaral, 2005, 2006, 2009). There are generally robust to heavy amygdala interconnections with multiple further cortical areas, and with subcortical brain regions. PRC relays heavily and reciprocally to lateral, basal and accessory basal nuclei, and these are likely the heaviest amygdala interconnections of all; this suggests they mediate a principal amygdala function.

\section{Perirhinal Cortex}

PRC integrates complex, multimodal, meaningful and finegrained, distributed object representations (Taylor et al., 2006, 2007, 2009; Cowell et al., 2010; Clarke et al., 2013; Mundy et al., 2013; Behrmann et al., 2016). Further, neural interconnections that are heavy and reciprocal support recurrent processing, that crucially facilitates the processing and development of meaningful, and fine-grained representations (Rossion et al., 2003, 2012; Hegdé, 2008; Cardin et al., 2011; Naci et al., 2012; Clarke et al., 2013; Kravitz et al., 2013; Martin, 2016; Sato et al., 2017a). Together, PRC's function, and the heavy and reciprocal interconnections of amygdala and PRC, suggest that amygdala likewise contributes meaningful and fine-grained representations for integration by PRC (Figure 1).

Complex, multimodal, and meaningful, distributed representations comprise sensory, motor and other specialized components that are distributed across the primate brain, and this is supported by neuroimaging studies and neuropsychological findings. For instance, faces and other complex objects are represented across multiple brain regions, the chief ones including inferior occipital cortex (IOC), fusiform gyrus (FG) and other subregions of VTC, STS, amygdala, insula, OFC and temporal pole (Allport, 1985; Rossion et al., 2003; Bouvier and Engel, 2006; Atkinson and Adolphs, 2011; Ku et al., 2011; Perrodin et al., 2015). Such distributed representations are integrated by means of nodes or hubs, which also efficiently reactivate those networks so as to achieve knowledge reactivation and retrieval (Barsalou et al., 2003; Barsalou, 2008; Martin, 2009; Meyer and Damasio, 2009). A major such hub is PRC (Taylor et al., 2006, 2007, 2009; Cowell et al., 2010; Clarke et al., 2013; Mundy et al., 2013; Behrmann et al., 2016). PRC's function of integrating complex, multimodal, meaningful and fine-grained, distributed object representations, is supported by neuropsychological and neuroimaging studies that place demands on such functions.

Human neuropsychological and monkey lesion studies report that lesions to PRC produce visual recognition and visual 


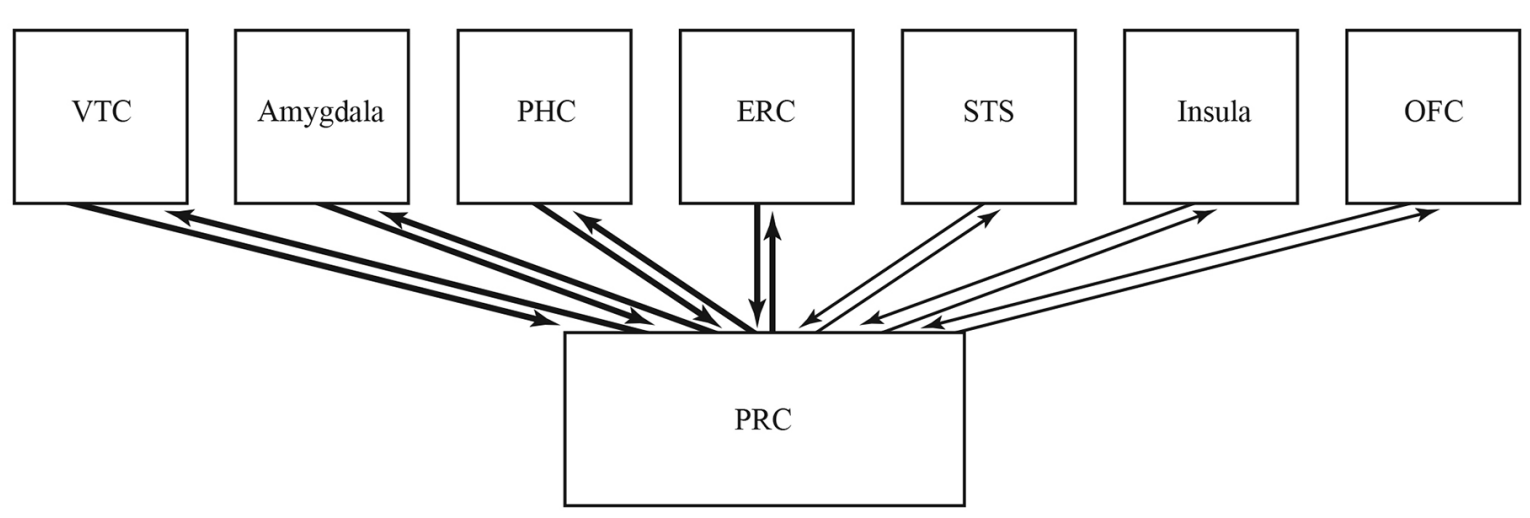

FIGURE 1 | Summary of the hypothesis. PRC integrates complex, multimodal, meaningful and fine-grained, distributed representations. Amygdala interconnects especially heavily and reciprocally with PRC, suggesting it contributes specialized representations for integration by PRC. Consistent with this, amygala represents such forms of intangible knowledge as valence, economic value, importance, noxiousness, social status, trustworthiness and social popularity. Taken together, it is hypothesized that amygala represents diverse forms of intangiable knowledge, that participate in distributed represntations of humans, objects and other stimuli. VTC, ventral temporal cortex; PHC, parahippocampal cortex; ERC, entorhined cortex; STS, superior temporal sulcus; OFC, orbitofrontal cortex; PRC, perirhined cortex.

discrimination impairments for complex object stimuli, but not for more basic ones (Lee et al., 2005, 2006; Saksida et al., 2007; Taylor et al., 2009; Cowell et al., 2010; Hoffman et al., 2014; Behrmann et al., 2016). Neuroimaging studies have examined brain activations during tasks of naming the presented pictures of common objects. The findings were that the task of general naming (e.g., animal, musical instrument) that requires coarse-grained representations, engaged posterior VTC regions, whereas the task of specific naming of the same objects (e.g., zebra, saxophone) that requires complex fine-grained representations, engaged these and additional regions including PRC (Tyler et al., 2004; Clarke and Tyler, 2014). Studies using related paradigms have reported concordant findings (Mundy et al., 2013; Abel et al., 2015; Mollo et al., 2017). Furthermore, temporal pole, PRC and adjacent anterior brain regions participate in recurrent processing with posterior brain regions during cognitive processing. This is evidenced by electroencephalographic (EEG) and magnetoencephalographic (MEG) neuroimaging, as well as transcranial magnetic stimulation (TMS) manipulations, during the performance of challenging object processing tasks (Naci et al., 2012; Chiou and Lambon Ralph, 2016; Mollo et al., 2017). Thus, convergent evidence supports meaningful and fine-grained representations being processed and integrated in PRC.

The formation of persisting knowledge representations results from consolidation processes, whereby initially transient neural activity is transformed into persisting neural representations (Brashers-Krug et al., 1996; Karni et al., 1998; Maquet, 2001). There is abundant and convergent evidence from rodent studies that consolidation is implemented in amygdala (Li et al., 2013; Cestari et al., 2014; LeDoux, 2014; Janak and Tye, 2015; Fanselow and Wassum, 2016; Schiff et al., 2017), including consolidation in the amygdala-PRC circuit (Perugini et al., 2012; Laing and Bashir, 2014). In addition, a study of seven surgical patients with intracranial electrodes implanted in amygdala, presented the patients with degraded fearful and happy faces, and their task was to judge the faces as either fearful or happy. It was found that neuronal activity of a subset of amygdala neurons encoded the patients' subjective judgments, rather than the physical features, of the face stimuli (Wang et al., 2014). Thus, amygdala encodes representations that are persisting and early evidence suggests likely meaningful too.

Taken together, knowledge representations are distributed across multiple specialized brain regions. Meaningful, fine-grained visual object representations, as well as high-level representations in other modalities, are processed and integrated into complex, multimodal, meaningful and fine-grained, distributed object representations by PRC (Taylor et al., 2006, 2007, 2009; Cowell et al., 2010; Clarke et al., 2013; Mundy et al., 2013; Behrmann et al., 2016). The interconnections of amygdala and PRC, which are especially heavy as well as reciprocal, amygdala implementation of consolidation processes, and early intracranial recording findings consistent with meaningful amygdala representations, together suggest that amygdala likewise contributes meaningful and fine-grained representations for integration by PRC. These representations are hypothesized to concern intangible knowledge. Intangible knowledge is an important component of cognition (see later section: significance for social processing), but it has been little researched as evidenced by few entries in the Medline database. There is no accepted definition, so it is provisionally defined as non-physical or non-concrete features of stimuli, that ubiquitously and substantively modulate behavior, cognition, and emotion. Likewise, the formation of intangible knowledge representations is little researched, but some forms of it are likely self-generated, often through interactions between body, brain and environment. In the next section, these cognitive hypotheses are supported with behavioral, neuroimaging, neuropsychological and physiological 
evidence, for amygdala's representation of diverse forms of intangible knowledge.

\section{BEHAVIORAL, NEUROIMAGING, NEUROPSYCHOLOGICAL AND PHYSIOLOGICAL EVIDENCE}

\section{Subjective Valence Representation}

In a study with rhesus monkeys, individual abstract visual images were paired with liquid reward, or aversive air-puffs. The monkeys successfully learned the valence (positive or negative) of each image, and this was expressed by behavioral responses of anticipatory licking or blinking, respectively. After training, the valences were reversed, so that images formerly paired with reward were now paired with air-puffs, and vice versa. Single-cell recording of amygdala neurons revealed that amygdala neuronal activity predominantly encoded image valence, and to a limited extent, image identity. Moreover, after the valence reversals, amygdala neuronal activity was rapidly modified to again reflect image valence (Paton et al., 2006). A subsequent single-cell recording study with rodents, reported that amygdala neurons preferentially encode positive or negative valence (consistent with Paton et al., 2006), and further that this is related to their anatomical projection targets (Beyeler et al., 2016).

A large literature has developed on sensory-specific satiety and its effects on the subjective valence of foods. Specifically, human or monkey subjects are allowed to eat a food until satiety. They are then presented with a choice of that food and another one, and their preference for the first food has commonly fallen relative to the pre-feeding baseline condition. That is, the subjective valence of that food falls during satiety (O'Doherty et al., 2000; Small et al., 2001; Murray and Rudebeck, 2013). Extensive investigations of the brain network underlying this effect indicate that amygdala, OFC and mediodorsal thalamus are involved (Machado and Bachevalier, 2007; Rudebeck and Murray, 2011; Murray and Rudebeck, 2013). Moreover, combining the sensory-specific satiety paradigm with transient inactivation of amygdala in monkey, revealed that amygdala generates revised valence representations of the satiated food (Wellman et al., 2005). Similarly, a human study using satiety manipulations and fMRI, found that subjective valence (attractiveness) representations of foods were mediated by amygdala (Piech et al., 2009). Such valence representations are relayed to anterior $\mathrm{OFC}$ which is likely an integrative hub for high-level multimodal food desirability representations (Kringelbach and Rolls, 2004; Rolls, 2005; Price, 2006; Piech et al., 2009; Murray and Rudebeck, 2013).

Further studies have used musical stimuli varying in subjective valence from unpleasantness to intense pleasantness or joyfulness, combined with fMRI or intracerebral electrode arrays to measure human brain activity. The findings were that amygdala is centrally involved in the network mediating musical valence representation (Koelsch et al., 2013; Koelsch and Skouras, 2014). Further, amygdala generates such representations with a relatively lengthy latency, and it modulates the activity of other major network regions, specifically auditory cortex and OFC (Kumar et al., 2012; Omigie et al., 2015a,b). These findings suggest a principal and high-level role of amygdala in the circuit mediating the subjective unpleasantness-pleasantness representations of music. Collectively, diverse paradigms support the generation and representation of subjective valence, a form of intangible knowledge, in amygdala.

\section{Impact Representation}

Amygdala likely processes the "impact" feature of stimuli. High impact features are those features that make stimuli striking and powerful, and often characterize photographs of trouble spots and crises across the world. In a study of this feature, healthy subjects were presented with photographs of stimuli that were high impact or low impact, as well as control stimuli, and inverted neutral stimuli. The task was to respond by button press to all inverted images, and subjects were neuroimaged with fMRI while they performed it. The findings were that high impact stimuli engaged amygdala, and this effect remained after controlling for such potential confounds as arousal, pleasantness, distinctiveness and visual complexity (Ewbank et al., 2009). Thus, amygdala mediates impact representations, a further form of intangible knowledge, but further replications of this finding are desirable.

\section{Economic Value Representation}

Amygdala participates in planning processes, and it represents the values of the benefits and other features of plans. In a physiological study, monkeys were presented with two cues on each trial. They could freely choose by means of saccades to one cue to consume a fruit juice reward immediately ("spend choices"), or they could choose by saccades to the other cue to defer consumption, and thus accumulate multiple fruit juice rewards ("save choices"), which were further augmented with "interest." Single cell recording of amygdala neurons during the performance of this task, revealed that separate populations of amygdala neurons proactively represented the economic value and length of plans, and that these were predictive of subsequent actions. Moreover, such representations were reset when a new plan commenced after a "spend choice," and were absent when plans were not engaged during instructed sequences of trials (Hernádi et al., 2015). The key findings above were replicated in a study using healthy human subjects and fMRI neuroimaging (Zangemeister et al., 2016).

\section{Noxiousness Representation}

The hypothesis that amygdala contributes noxiousness representations, generated from nociceptive experiences, to distributed object representations has not been explicitly examined, but is supported by the behavioral study of Kavaliers et al. (1999). Initially, deer mice have no knowledge of biting stable flies, as they do not attempt to avoid those that have had their mouthparts surgically removed. After having been bitten by intact biting stable flies, however, the deer mice on subsequent encounters burrow and take other actions to avoid the biting stable flies, as well as activate endogenous analgesic processes, as demonstrated by the hotplate test. They engage 
in the same activities even on encountering stable flies whose mouthparts have been surgically removed, so cannot have bitten them. In contrast, the deer mice do not manifest such behaviors when encountering visually similar but non-biting houseflies (Kavaliers et al., 1999). Thus, deer mice evidently form knowledge representations that specifically relate to stable flies and incorporate their noxious character. It appears likely that the crucial interactions that give rise to the latter representation are the stable flies' bites and the resulting pain suffered by the deer mice (Kavaliers et al., 1999). Together, environment, body, and brain collaborate to generate specific adaptive knowledge, in accordance with embodied cognition.

Amygdala likely plays a crucial role in these effects for multiple reasons. Fear conditioning experiments, which possess common features with the Kavaliers et al.'s (1999) design but use electric shocks instead, have demonstrated an important contribution for amygdala (LeDoux, 2014; Fanselow and Wassum, 2016; Schiff et al., 2017). Nociceptive information is relayed to amygdala, as summarized earlier, and there is substantive evidence that consolidation of nociceptive activations is implemented in amygdala (Neugebauer et al., 2003; Bird et al., 2005; Ikeda et al., 2007; Veinante et al., 2013; Neugebauer, 2015; Shinohara et al., 2017). In addition, disruption of consolidation in a related study by means of injection of NMDA receptor antagonist into the peritoneum of deer mice, was found to abolish the adaptive behaviors and analgesia (Kavaliers et al., 1999, Experiment 2). These results also parallel those in fear conditioning studies (Fanselow and Kim, 1994; Goosens and Maren, 2004) and are consistent with a substantive role for amygdala. Further, encounters of experienced deer mice with biting stable flies elicited endogenous analgesia, which is known to crucially involve amygdala (Helmstetter et al., 1998; Bingel et al., 2006; Eippert et al., 2009; Rouwette et al., 2012; Veinante et al., 2013; Maire et al., 2016), further supporting its involvement. Additionally, amygdala lesions or inactivation performed in pain experiments have not affected baseline levels of pain sensitivity nor of latency of pain responses (Fox and Sorenson, 1994; Bernard et al., 1995; Manning et al., 2001, 2003; Veinante et al., 2013); amygdala also modulates cognition during pain (Veinante et al., 2013); together these findings support amygdala mediation of high-level pain-related functions. In summary, the nociceptive effects of stable fly bites lead deer mice to generate specific knowledge representations of those insects that include their noxious character, and it is suggested the latter representation comprising intangible knowledge, is mediated by amygdala.

\section{Importance Representation}

Amygdala has long been suggested to represent significance or importance (Geschwind, 1965; Gloor et al., 1982; Amaral and Price, 1984; Sander et al., 2003; LaBar and Warren, 2009; Phelps, 2009; Adolphs, 2010; Pessoa and Adolphs, 2010), and it may generate such representations on embodied cognition principles. A stimulus characterized by importance is one "having much import or significance; carrying with it great or serious consequences; weighty, momentous, grave, significant," as defined by the Oxford English Dictionary Online (1989).
An instance in modern times is that employees regard their employers and their associated powers as important, as employees can experience great consequences (promotion, unemployment) from interactions with their employer. Important stimuli mobilize enhanced arousal, effort, perceptual processing, attention, cognition and other functions in an individual, so that the important stimuli can be met with prepared and proportionate resources.

Amygdala participates in distributed representations (see earlier), and it can drive the above enhanced functions for important stimuli, because it projects to an extensive array of brain regions (Amaral and Price, 1984; Young et al., 1994; McDonald, 1998; Freese and Amaral, 2009). Specifically, amygdala (predominantly the central nucleus) projects heavily to hypothalamus and NTS, projects to an array of brainstem regions, including the reticular formation, periacqueductal gray, laterodorsal tegmental nucleus, ventral tegmental area, locus coeruleus and dorsal motor nucleus of the vagus, and projects heavily and reciprocally to the parabrachial complex (PBC; Davis, 1992; Bernard et al., 1993, 1995; Pitkänen, 2000; Freese and Amaral, 2009). Such projections enable amygdala to enhance arousal and effort through modulation of ANS, hormonal, cardiovascular, respiratory, digestive and other visceral systems.

Amygdala sends heavy and excitatory projections to visual cortical areas (Amaral and Price, 1984; McDonald, 1998; Freese and Amaral, 2005, 2006, 2009) enabling it to enhance visual perceptual processing and attention. Amygdala-driven enhancement of vision and attention is further supported by human neuropsychological and monkey lesion findings, that provocative stimuli that enhanced visual processing in healthy controls, did not do so in patients and monkeys with amygdala lesions and intact visual cortex (Anderson and Phelps, 2001; Vuilleumier et al., 2004; Hadj-Bouziane et al., 2012). Projections from amygdala to auditory cortical areas (Amaral and Price, 1984; McDonald, 1998; Pitkänen, 2000; Yukie, 2002; Freese and Amaral, 2009), enable amygdala to drive similar perceptual and attentional enhancements in that modality (Kumar et al., 2012; Omigie et al., 2015b). In addition, amygdala can drive persisting representational changes and specialization in sensory cortical areas (Chavez et al., 2009, 2013). Amygdala also projects to frontal cortex, including heavily to ACC, BA 45 in VLPFC and anterior insula (Amaral and Price, 1984; Freese and Amaral, 2009; Vogt, 2009; Gerbella et al., 2014), likely enabling it to enhance cognitive function. Taken together, amygdala participation in stimulus representations and its extensive connectivity, enable amygdala representations to predictively enhance a network of functions that together likely constitute importance, a form of intangible knowledge. Moreover, this arrangement is consistent with predictive coding being a major strategy of the brain (Nadel and Hardt, 2011; Weston, 2012; Smith and Goodale, 2015; Saker et al., 2018), including of amygdala (Hernádi et al., 2015; Zangemeister et al., 2016).

Importance representations may develop through embodied cognition processes. For instance, in the hyperarousal form of PTSD, during the traumatic event (peritrauma) traumatic stimuli provoke extreme levels of arousal (hyperarousal) and 
related responses. The individual involuntarily replicates these intense responses on subsequently encountering trauma-related reminders; in other words, these reminders are characterized by extreme importance. Amygdala processing of peritraumatic bodily responses likely underlies these effects; in contrast, a study of identical twins discordant for PTSD, found genetic influences to be non-significant (Koenigs et al., 2008; Gilbertson et al., 2010; Weston, 2014). PTSD is at the extreme of the stress continuum (Ruscio et al., 2002; Forbes et al., 2005; Broman-Fulks et al., 2006), so the above processes may generalize, but this issue awaits investigation.

\section{Exclusiveness Representation}

A very different experimental paradigm involved ewes; these animals normally form a specific memory of the scent of their own newborn offspring in the $2 \mathrm{~h}$ after birth, and they subsequently suckle their own offspring only while aggressively rejecting all others. Transient inactivation by lidocaine over the critical period of the cortical or medial amygdaloid nuclei resulted in indiscriminate suckling, although olfactory perception and memory retrieval were unimpaired (Keller et al., 2004). In addition, inactivation of the ewe's olfactory system has been found to disrupt selective nursing behavior (Lévy et al., 1995; Ferreira et al., 2000). It is hypothesized that in the Keller et al. (2004) inactivation study, the ewes perceived the scent of their own offspring but failed to regard it as "exclusive" or "special," which is likely mediated by the cortical or medial amygdaloid nuclei. Related modulatory findings mediated by rodent amygdala have been reported (Demas et al., 1997; Petrulis, 2009; Gur et al., 2014). Thus, amygdala likely mediates this further form of intangible knowledge, and environment, body and brain collaborate in ewes to produce specific adaptive knowledge, as proposed by embodied cognition.

\section{Ingroup Membership Representation}

Cooperation among conspecifics is widespread among animals, and is strongly developed in human. It is a factor that is similarly or more important than competition-related factors such as dominance, in the achievement of health and reproductive success in human and other primates (Platt et al., 2016; Schmelz and Call, 2016; Hare, 2017). Humans rapidly form social groups, and simply belonging to a group (e.g., as a result of random allocation in experiments) leads to richer and more complex representations and amplified processing of ingroup members. For instance, belonging to a group leads to more detailed and individuated perceptual processing, greater liking and amplified processing, of ingroup members (Van Bavel et al., 2008, 2011; Cikara and Van Bavel, 2014; Guassi Moreira et al., 2017). The network that mediates the representation and amplified processing of ingroup members has been found by fMRI neuroimaging to involve amygdala, OFC, FG and striatum (Van Bavel et al., 2008, 2011; Cikara and Van Bavel, 2014; Guassi Moreira et al., 2017). Thus, amygdala participates in ingroup representation, a form of intangible knowledge, although further work is needed to more precisely specify its contribution.

\section{Social Status Representation}

A number of studies have examined the formation and encoding of social status representations, in monkey and human. In a study of 25 group-living macaque monkeys, status relationships were measured through observation and recording of the behavioral interactions between animals. The animals' neural structure and function were also measured by structural and functional MRI, respectively. The findings were that social status was positively related to gray matter (GM) volume of amygdala, hypothalamus, brainstem subareas and mid STS all bilaterally, as well as hippocampus and anterior DLPFC unilaterally. Social status was negatively related to GM volume of basal ganglia subregions and dorsal septum bilaterally. In addition, findings were reported of resting functional coupling between amygdala and hypothalamus, as well as amygdala and brainstem subregions, that were significantly associated with status (Noonan et al., 2014).

In two human neuroimaging studies, during training sessions a set of human faces were presented, and subjects were required to learn by trial and error the individuals' status within the linear social hierarchy. Subjects were tested during testing sessions interleaved with training sessions, and were required to indicate an individual's status, and give a confidence rating in their answer. The findings of functional neuroimaging were again that a network of brain regions generates and encodes social status representations, principally bilateral amygdala, bilateral anterior hippocampus, posterior hippocampus, ventromedial prefrontal cortex (VMPFC; BAs 24, 32, 9), and FG. Further, structural neuroimaging revealed that variation in subjects' performance was significantly predicted by variation in GM volume, only of amygdala bilaterally (Kumaran et al., 2012, 2016). Moreover, the brain regions summarized above have been reported across diverse paradigms, that have investigated the formation and encoding of social status representations (see for review, Watanabe and Yamamoto, 2015). In addition, the contributions of regions within the network are being clarified. Specifically, Bayesian modeling of behavioral performance and its correlation with neural activation, suggests that VMPFC (BAs 24, 32, 9) forms and updates particular social status representations, and relays these to amygdala and hippocampus. Amygdala likely represents social status knowledge, which is also activated automatically. Posterior hippocampus likely represents linear hierarchies more generally (Kumaran et al., 2012, 2016). Taken together, there is robust evidence from diverse paradigms in monkey and man, that amygdala is a principal region in the representation of knowledge of social status, a further form of intangible knowledge. Moreover, status is learned through interactions with other individuals in a hierarchy.

\section{Popularity Representation}

Individuals vary in popularity, which is represented by a small network that includes amygdala. The popularity of a member of a group can be quantified, by combining the ratings of liking given by fellow group members for that individual. In a study of the neural representation of popularity, members of two real-world voluntary groups of 13 members each, completed questionnaires requiring ratings of liking of 
other group members, and other variables, and had their faces photographed. During fMRI neuroimaging, each group member viewed the faces of group members and performed a simple cover task. The findings were that popularity was represented by a small network, comprising amygdala, VMPFC and ventral striatum. These findings remained after controlling for potential confounds, such as facial attractiveness, sex and interpersonal closeness; additionally, brain regions' identities were determined with independent functional localizer tasks performed in the same scanning session (Zerubavel et al., 2015). Thus, amygdala participates in the representation of popularity, another form of intangible knowledge. Replications of this finding are desirable, as are findings from additional research paradigms (e.g., neuropsychology, single-cell recordings), as well as more precise specification of the contribution of amygdala to popularity representation.

\section{Trustworthiness Representation}

Amygdala is a major part of the network that mediates trustworthiness, more specifically untrustworthiness, and this is supported by neuroimaging and neuropsychological findings. In a meta-analysis of PET and fMRI neuroimaging studies of trustworthiness represented in facial stimuli, it was found that reducing levels of trustworthiness (i.e., untrustworthiness) were associated with consistent activation of amygdala, as well as of anterior insula, VLPFC, inferior frontal gyrus (IFG) and part of the basal ganglia (Mende-Siedlecki et al., 2013). A subsequent meta-analysis of fMRI studies of trustworthiness represented in facial stimuli, again found amygdala involvement in untrustworthiness representation (Santos et al., 2016). In such studies, however, potential confounding variables such as inadvertent processing of facial attractiveness, may be affecting the findings (Mende-Siedlecki et al., 2013).

Neuropsychological approaches have examined patients with amygdala lesions, mostly brought about by disease or surgical excisions to treat epilepsy. In a study of three patients with bilateral amygdala lesions, varied facial stimuli of unfamiliar persons were presented, and the findings were that the patients were significantly impaired in trustworthiness ratings relative to neuropsychological and normal controls (Adolphs et al., 1998). A larger neuropsychological study used a group of 32 patients with unilateral amygdala lesions, a brain damage control group with focal brain lesions of any region other than amygdala, insula, or VMPFC, and a healthy control group (Koscik and Tranel, 2011). The task did not involve facial stimuli but playing the Trust Game, which entailed participating in 40 rounds of monetary exchanges with a computer player. Variables included the money given by the computer player, and the subjects' monetary responses; these and the sums accumulated by the players were displayed to subjects. The findings were that whereas the healthy control group engaged in a tit for tat exchange strategy, the amygdala lesion patients responded to decreased or unchanged sums of money from the computer player with increased sums. These findings were interpreted as a failure to generate and represent appropriate distrust during interactions with the Trust Game player, and were associated with amygdala damage (Koscik and Tranel, 2011). More generally, behavioral studies have found that trust is likely learned through experiences, rather than being a prespecified disposition (Glanville and Paxton, 2007). In sum, substantive evidence supports the hypothesis that amygdala mediates untrustworthiness, a form of intangible knowledge. Moreover, the Koscik and Tranel (2011) findings suggest that amygdala may generate through experience this form of intangible knowledge.

\section{Moral Representations}

Moral knowledge and judgments are a further form of intangible representation in which amygdala participates. An fMRI neuroimaging study required subjects to estimate how much money was contained in pictured transparent jars that were partly filled with penny coins across a series of trials. Subjects were incentivized by a reward structure to give inaccurate estimates (overestimates or underestimates), that in different experimental conditions benefited or harmed themselves or an associate. The behavioral findings were that self-benefitting dishonesty measures escalated across trials, consistent with reports that minor transgressions can snowball into major ones. The neuroimaging findings were that dishonesty that is self-serving and weighted by position in the succession of trials, was significantly associated with reducing activity of amygdala and anterior insula. In addition, reducing activation of amygdala across two trials in response to dishonesty, was found to predict the escalation in self-serving dishonesty on the following trial (Garrett et al., 2016). Thus, amygdala may encode some form of moral standards, whose weakening permits escalating dishonesty. Two meta-analyses have examined brain activations engaged by moral tasks. Both found consistent and reliable involvement of a network of areas, that included amygdala, OFC, MPFC, TPJ and precuneus (Bzdok et al., 2012; Eres et al., 2018). The contribution of each region in the network requires to be specified. In sum, amygdala reliably participates in the network that represents moral knowledge, another form of intangible knowledge, and some insight into amygdala's contribution is offered by the Garrett et al.'s (2016) study.

\section{Further Observations and Summary}

A number of intangible knowledge representations in which amygdala participates, have now been summarized. These findings have accumulated through some perceptive insights (e.g., Adolphs et al., 1998; Ewbank et al., 2009; Kumaran et al., 2012), rather than through deliberate focus on the domain of intangible knowledge representation. Additional amygdala intangible representations are likely to be revealed. In a physiological study, a rich range of visual object images was presented to monkeys who passively viewed them, while responses of a large sample of amygdala neurons were recorded. The findings were that similar proportions of amygdala neurons responded differentially to monkey faces, human faces, or most other objects. Moreover, many amygdala neurons responded quite differently to visually similar stimuli (Gothard et al., 2007), which suggests the neurons were processing features that have yet to be identified.

It has been hypothesized that amygdala's principal representations may lie on a continuum of negative to positive 
valence, or "good to bad" (e.g., Paton et al., 2006; Koelsch and Skouras, 2014; Janak and Tye, 2015). It is suggested instead that amygdala may be better conceived as mediating a diversity of independent representations. That amygdalamediated intangible knowledge representations are frequently independent, is supported by findings that social status and trustworthiness were not significantly correlated (Kumaran et al., 2012); social status was independent from social network size (Noonan et al., 2014); the impact feature representation was found after controlling for valence, arousal and other features (Ewbank et al., 2009); and amygdala neuronal activity encoding the economic value and length of plans differed substantially from that encoding reward (Hernádi et al., 2015; Zangemeister et al., 2016). Neuroanatomically, amygdala receives neural inputs that include those concerning visual objects, visual motion, audition, taste, the fattiness and grittiness of foods, temperature of foods, bodily temperature, other viscerosensations, blood acidity changes, epinephrine levels, cortisol levels, nociception and so forth (see earlier). Such wide diversity of inputs is suggestive of diverse representations being mediated by amygdala. In addition, the especially heavy and reciprocal interconnections of amygdala and PRC, which integrates fine-grained representations, are consistent with amygdala relaying a multitude of fine-grained representations to PRC; if only few coarse-grained representations needed to be processed, they would be unlikely to require such heavy and particular neural resources. Thus, this evidence supports amygdala mediation of diverse representations, but it does not resolve the issue. Hence, more direct and systematic tests are needed to definitively settle this issue, as set out in the penultimate section.

The diversity of amygdala representations likely contributes to adaptation. Dubos conceived the essence of adaptation as follows:

The real measure of health is not the utopian absence of all disease but the ability to function effectively within a given environment. And since the environment keeps changing, good health is a process of continuous adaptation to the myriad microbes, irritants, pressures and problems that daily challenge man (Dubos, 1990, p. 95).

That is, environments are highly complex, variable, and unforeseeable and individuals must continually achieve specific and tailored adaptation to the particular conditions in which they live. Amygdala's potential for diverse and fine-grained representations can answer such demands. In addition, it is optimal for such representations to be elaborated through experience of the particular environment rather than to be prespecified in the genome. In other words, initially domaingeneral encoding may be elaborated through interactions with the environment into domain-specific and fine-grained representations that are tailored to the particular conditions. For example, amygdala receives nociceptive system projections, which may be regarded as domain-general. Through interactions with biting insects, which involve body, environment and brain as envisaged by embodied cognition, representations that specific insects are noxious are generated (Kavaliers et al., 1999).
This elaboration of fine-grained representations is consistent with the proposal of Spunt and Adolphs (2017) that domaingeneral systems may through their structural connectivity, inputs and intrinsic computations, become domain-specific. Amygdala representations may also be computed by other means, such as in other brain regions that relay them to amygdala. This overall hypothesis is also consistent with findings that human cortical organization is "relaxed." That is, in human there is high genetic control of brain size, but lower genetic control of cortical organization, particularly of high-level cortical areas, which enables increased levels of plasticity and neural circuit specialization (Gómez-Robles et al., 2015). A contrary view, however, holds that amygdala circuits may involve strong genetic prespecification (Gore et al., 2015; Beyeler et al., 2016). Currently, the formation of amygdala representations is poorly understood, so empirical studies are needed to test between these hypotheses.

In summary, the novel hypothesis is presented that a principal function of amygdala is the mediation of diverse, independent and fine-grained intangible knowledge representations, which are integrated into multimodal, meaningful and fine-grained distributed knowledge representations. Such amygdala representations encompass non-social knowledge (e.g., valence, noxiousness, economic value) and social knowledge (e.g., social status, trustworthiness, popularity). The hypothesis has considerable explanatory potential with regard to unanswered questions in several domains, as demonstrated in the next section.

\section{SIGNIFICANCE FOR SOCIAL PROCESSING; CLINICAL SIGNIFICANCE}

\section{Significance for Social Processing}

Amygdala participates in social processing, and there is convergent evidence for this. In human and other primates, structural studies have found the volume of amygdala and other brain regions to be significantly and positively associated with the size and complexity of social networks (Barton and Aggleton, 2000; Bickart et al., 2011; Sallet et al., 2011; Von Der Heide et al., 2014). Moreover, in Sallet et al. (2011), social group size had been independently imposed on the monkey subjects, hence social network size likely drove this amygdala volume increase. Increased brain region volumes that were also associated with social network size included those of several temporal areas, anterior PFC and ACC (Sallet et al., 2011; Von Der Heide et al., 2014). Functional neuroimaging and electrophysiological studies of social tasks have also reported consistent amygdala activation, hence its inclusion in the "social brain" (Atkinson and Adolphs, 2011; Ku et al., 2011; Gotts et al., 2012; Von Der Heide et al., 2014; Rutishauser et al., 2015; Patriquin et al., 2016).

Amygdala, however, does not encode actual social behaviors. In experimental lesion studies, selective ibotenic acid lesions were made to amygdala bilaterally at 2 weeks after birth in macaque monkey infants, and the animals were observed and tested behaviorally over subsequent years. The findings were that infant-mother interactions and behaviors, as well as the speciestypical repertoire of social behaviors, did not differ from those 
of controls. The young animals did, however, manifest a number of modest behavioral anomalies, such as retrieving without delay food placed adjacent to a fearful object such as a model snake, and displayed limited exploration of objects in some conditions but not in others (Prather et al., 2001; Machado and Bachevalier, 2003; Bauman and Amaral, 2011). When mature, the animals became less sociable in that they groomed others less, spent more time alone but alert, and females expressed little interest in the infants of other females. The animals also expressed more anxiety-related behaviors, and performed more self-directed stereotypies (Toscano et al., 2009; Moadab et al., 2015). Hence, amygdala does not directly encode social behaviors; instead its contribution is indirect and modulatory (Adolphs, 2010; Bauman and Amaral, 2011), but there is no consensus on the nature of it.

It is hypothesized that amygdala's contribution is that of intangible knowledge, which differentially affects social behaviors compared to other behaviors. Specifically, conspecifics are commonly characterized in terms of being, for instance: supportive, caring, kind, loyal, faithful, important, trustworthy, interdependent, dishonest, hostile, critical, tolerant, constructive, understanding, appreciative, respectful, contemptuous, fair, dominant, subordinate, interesting, close, special, rich, aggressive and so forth. Moreover, many of these features have major roles in social relationships (e.g., Wright, 1985; Reynolds and Mansfield, 1999; Gilligan, 2000; Rachman, 2010; Lavner and Bradbury, 2012; Platt et al., 2016; Fincham and May, 2017). In contrast, other objects and stimuli are infrequently so characterized. That is, intangible knowledge processing is more extensive, critical, and finer-grained in social contexts. Amygdala processes some of these features, which may explain its influence on social processing, and its expansion with larger and more complex social networks (Barton and Aggleton, 2000; Bickart et al., 2011; Sallet et al., 2011; Von Der Heide et al., 2014). Amygdala disruption, moreover, is likely to preferentially impair social cognition and social interactions, as occurs in ASD and is discussed next.

\section{Clinical Significance: Autism Spectrum Disorder}

\section{Amygdala Is Disrupted in ASD}

Amygdala is commonly disrupted in ASD, and the presented amygdala hypothesis offers testable explanations of a number of prominent but unexplained ASD symptoms and features. Amygdala dysfunction in ASD has long been suggested (Bachevalier, 1994; Baron-Cohen et al., 2000) and is supported by functional evidence, which includes neuroimaging findings of amygdala functional abnormalities (see for meta-analysis, Patriquin et al., 2016), and electrophysiological findings in two ASD patients of abnormal selectivity of a subpopulation of amygdala neurons (Rutishauser et al., 2013). In addition, deep brain stimulation of basolateral amygdala but not adjacent brain regions, was found to ameliorate numerous ASD symptoms, as well as self-injurious behaviors (Sturm et al., 2013). Structural evidence includes structural neuroimaging findings of reduced amygdala volume in adolescents and adults (Stanfield et al., 2008; Schumann and Amaral, 2009; Via et al., 2011; Sato et al., 2017b), cellular findings of reduced amygdala neuron numbers (Schumann and Amaral, 2006) or amygdala neuron density (Wegiel et al., 2014), and findings of an abnormal amygdala growth trajectory that is also associated with ASD symptomatology (Munson et al., 2006; Nacewicz et al., 2006; Stanfield et al., 2008; Schumann and Amaral, 2009; Schumann et al., 2009; Kim et al., 2010). Together, these provide robust and convergent evidence of amygdala disruption in ASD. Such disruption can likely explain the following ASD symptoms and features.

\section{Disorganized Scanpaths and Apparent Social Disinterest}

A core feature that manifests early, persists throughout life, is independent of IQ, and whose mechanism is unclear (Frazier et al., 2017), is the disorganized visual scanpaths of ASD individuals. Specifically, eye-tracking recordings of TD controls' scanpaths of scenes reveal that such scanpaths are organized and selective. Stimuli such as humans, their faces, and eyes commonly receive the majority of visual processing, whereas trivial stimuli receive fleeting processing at most (Klin et al., 2002, 2003, 2009). These and other findings suggest that importance, valence, salience, arousingness, and other intangible features are major factors in the organizing of scanpaths (Niu et al., 2012; Vuilleumier, 2015; Schomaker et al., 2017). ASD individuals' visual scanning of scenes, in contrast, is atypical: it is unorganized, unselective, and almost random (e.g., Klin et al., 2002, 2003, 2009; see for meta-analysis, Frazier et al., 2017). ASD individuals' object recognition and face recognition, however, are essentially intact (Jemel et al., 2006; Simmons et al., 2009; Weigelt et al., 2012). When orderly scanpaths in ASD have been reported, moreover, they were found to be driven not by intangible knowledge as in TD individuals, but by physical aspects of the scene, namely audio-visual synchronies (Klin et al., 2009). A subsequent fine-grained study examined ASD and TD individuals' visual scanpaths that were executed while viewing complex naturalistic images. It was found that ASD differences in scanpaths did not emerge early at the basic visual or object levels, but emerged later in the time course of viewing and particularly at the level of processing of meaning. Moreover, fixations to social stimuli were delayed, whereas fixations to artifactual stimuli were speeded (Wang et al., 2015). Taken together, it is hypothesized that deficits of intangible knowledge are sufficient to induce the commonly unorganized visual scanpaths in ASD. Moreover, amygdala mediates intangible knowledge, and it participates in the organizing of scanpaths (Gonzalez Andino and Grave de Peralta Menendez, 2012), hence its disruption may underlie ASD scanpath disorganization.

Auditory stimuli such as parents' voices, the individual's own name being called, and language sounds, commonly elicit interest in TD children. ASD children, in contrast, are frequently unresponsive to their parents' voices, to their own name being called, and to language sounds, according to observational and experimental evidence (Kanner, 1943; Klin, 1991; Jolliffe et al., 1992; Nadig et al., 2007; Miller et al., 2017). Basic sensory function, however, is found by audiometric tests to be normal in the great majority of ASD individuals (Tharpe et al., 2006; Tas 
et al., 2007). Similarly in the visual modality, ASD individuals are commonly reported to be apparently uninterested in fellow humans, including family members, peers, acquaintances, and social relationships generally, despite intact face recognition (American Psychiatric Association, 2013; Kanner, 1943; Jolliffe et al., 1992; Simmons et al., 2009; Weigelt et al., 2012).

At the neural level, TD individuals show enhanced high-level auditory cortex processing of human speech sounds; in contrast, ASD individuals commonly fail to show such enhanced high-level cortical processing. Nevertheless, corresponding processing of acoustically and complexity matched control sounds does not differ significantly between ASD and TD groups as measured by fMRI or event-related brain potentials (Ceponiene et al., 2003; Gervais et al., 2004; Lepistö et al., 2005; Whitehouse and Bishop, 2008). Similarly in the visual modality, high-level visual area FG has the capacity for normal levels of activation, but is commonly hypoactive when performing social tasks, and this has been ascribed to impaired modulation (Grelotti et al., 2005; Pierce and Redcay, 2008; Perlman et al., 2011; Patriquin et al., 2016). Together, these findings suggest there is a failure of enhancement of otherwise intact auditory and visual cortical processing in ASD individuals. This is suggested to manifest as apparent indifference to parents, peers, own name being called, speech, and so forth. Amygdala disruption likely participates in such impaired enhancement. Amygdala is heavily and extensively interconnected with visual cortex, and has an excitatory effect on it (Freese and Amaral, 2005, 2006, 2009; Smith et al., 2009). Further, in a monkey lesion study, facial expressions were found to enhance visual cortical activity in control animals, but such enhancement was abolished in monkeys with amygdala lesions (Hadj-Bouziane et al., 2012). Moreover in ASD, connectivity between amygdala and FG is reduced, and the latter is commonly hypoactive (Conturo et al., 2008; Kleinhans et al., 2008; Patriquin et al., 2016). Taken together, further studies are required, but current evidence is consistent with the hypothesis that apparent disinterest in visual social stimuli in ASD, likely arises from impaired enhancement of activity in high-level visual cortex, which is likely driven by amygdala disruption (see Kleinhans et al., 2011; HadjBouziane et al., 2012). Corresponding processes in high-level auditory cortex, which is also hypoactive in ASD (see above), and is interconnected with amygdala (McDonald, 1998; Yukie, 2002; Freese and Amaral, 2009), are plausible and require testing.

A further marked feature is the inability to understand social situations reported by ASD individuals (Jolliffe et al., 1992; Williams, 1996; Grandin, 2005). Given their intact physical knowledge but impairments at the meaning level (see above), it is hypothesized that impaired intangible knowledge likely contributes. Furthermore, this impairment in understanding has been reported as a major source of the stress and dysphoric emotions that are a common feature of ASD (Jolliffe et al., 1992; Williams, 1996; Grandin, 2005).

\section{Preference for Concrete Cognition}

Amygdala dysfunction may explain the preference for concrete and mechanical cognition in ASD, a feature which is evidenced by multiple findings (Baron-Cohen and Wheelwright, 1999; Klin and Jones, 2006; Klin et al., 2007, 2009; Ropar and Peebles, 2007; Wang et al., 2015). Generally, an impaired brain system can facilitate enhanced use and development of brain systems remaining intact, and this has been reported for diverse brain diseases that affected disparate brain regions (Kapur, 1996; Miller et al., 1998, 2000; Thomas-Anterion et al., 2010; Schott, 2012; Midorikawa and Kawamura, 2015). For example, anterior temporal lobe degeneration, which manifests in social and language impairments, can co-occur with posterior parieto-occipital enhancement, which is associated with outstanding artistic development (Miller et al., 2000; Schott, 2012; Midorikawa and Kawamura, 2015). Correspondingly in ASD, impaired neural systems for intangible cognition are suggested to facilitate enhanced use and development of preserved systems for concrete and mechanical cognition. Hence, the strongly developed and prominent concrete and mechanical cognition that is frequently reported in ASD.

\section{Heterogeneity of ASD}

Heterogeneity characterizes most medical disorders (Lawrie, 2017), but it is particularly severe in ASD (Schumann et al., 2011), and impedes progress in understanding of the mechanisms of the disorder. Amygdala is commonly regarded as mediating a homogeneous class of representations such as valence or fear (see earlier), rendering the heterogeneity of ASD difficult to comprehend. Amygdala, however, likely mediates a diversity of independent representations as argued above, rendering ASD heterogeneity more intelligible. For example, inputs to amygdala, which is one of the most widely interconnected of brain regions (Young et al., 1994), include visual, oral somatosensory, nociceptive, blood acidity and stress hormone inputs, which likely participate in different amygdala representations. Hence, for the richly interconnected amygdala, disrupted inputs that vary in number and in combinations, will elicit unusually heterogeneous patterns of impairments. Moreover, any one dysfunction is unlikely to be universal in ASD (see Rapin, 2006). Thus, amygdala's diversity of connectivity and functions is likely a substantive contributor to ASD heterogeneity.

\section{Activities of Daily Living}

Impaired activities of daily living in ASD are widespread, disproportionate to IQ, particularly disabling, stressful both for the affected individuals and their carers, and the mechanisms are unclear (Green et al., 2000; Howlin et al., 2013; Duncan and Bishop, 2015). It is likely that an inability to plan underlies impairments in some routine activities, such as making phone calls, handling money and using public transport (Green et al., 2000). Amygdala participates in planning processes (Hernádi et al., 2015; Zangemeister et al., 2016), hence it is hypothesized that amygdala dysfunction may participate in the impairment of such daily living activities. In addition, impaired trustworthiness representations likely contribute to social naivety and vulnerability, and impaired noxiousness representations to an inability to appreciate the dangerousness of objects and situations (see American Psychiatric Association, 
1994, 2013; Wing, 1976), which are further features that impair daily living in ASD. In summary, the presented amygdala hypothesis offers testable explanations of a number of prominent but poorly understood symptoms and features of ASD. A comprehensive account of ASD symptomatology, however, will involve dysfunctions of additional brain regions.

\section{CAUTIONS AND DIRECTIONS FOR FUTURE RESEARCH}

The generation and representation of intangible knowledge has been little researched, and more extensive studies of its contributions to cognition, and of amygdala's contributions are needed. Diverse studies have examined the representation of trust in the brain, and similar research attention should focus on further forms of intangible knowledge, which have often been investigated by few studies. The forms of intangible knowledge that are important in social relationships and social living, need to be delineated and merit more research attention.

Almost all sensory systems relay strongly to amygdala, predominantly to the lateral and basal nuclei, and these same nuclei relay heavily and reciprocally to PRC, as summarized earlier. This pattern of connectivity suggests the existence of significant neural circuits but these have not been examined. Their existence may be tested by means of diffusion tensor imaging in human, or by transneuronal viral tracers in monkey. The structure of these pathways suggests, interactive, recurrent processing, which is engaged in the formation of fine-grained, meaningful representations (see earlier). Such processing has been demonstrated in the vision-amygdala pathway (Sato et al., 2017a); the prediction of such processing in the amygdala-PRC pathway could be tested with intracranial electroencephalography in suitable but rare human patients, or single-cell recording in monkey.

The hypothesized diversity of amygdala-mediated representations raises a number of questions. Is the diversity real or an artifact of the experimental paradigms? There is some evidence that various amygdala representations are independent (e.g., Ewbank et al., 2009; Kumaran et al., 2012), but it is not sufficient. Future investigations of a particular amygdala representation should also examine potentially overlapping constructs, so as to be able to test systematically and explicitly, amygdala representations in terms of distinctiveness, fine-grained nature, or independance from fear, valence, and so forth. How does the diversity come about? It is likely that differing inputs may partly account for different representations. For example, pain, stress hormone, and gustatory inputs to amygdala are suggested to be processed to generate corresponding representations, such as noxiousness, importance, and valence, respectively. A useful strategy would be to examine disruptions of particular sensory systems or other inputs to amygdala, and their associations with particular forms of intangible knowledge impairment, as was illustrated by Kavaliers et al. (1999). In addition, replications of the Kavaliers et al.'s (1999) study are desirable, and verification needed that amygdala is indeed crucially involved in this processing. Amygdala receives high-level visual and auditory inputs, engages in markedly lengthy processing of them, and generates representations that differ from those of the sensory inputs (Wang et al., 2014; Omigie et al., 2015a; Minxha et al., 2017). The nature of the amygdaloid computations performed, and how the amygdaloid inputs and outputs differ, should further illuminate representation formation. How can the proposed representational diversity be encoded? The challenge of encoding a rich diversity of representations in a common region of brain tissue, has been answered in other brain regions, such as VTC. The latter encodes an infinite variety of face and other object forms by means of a powerful coding strategy, population coding. That is, the forms of diverse stimuli are encoded by means of different patterns of activation across a common region of cortex (Rolls, 2000; Haxby et al., 2004). The operation of population coding in monkey amygdala has been reported by Rolls (2000), and requires more detailed investigation.

In ASD, impaired intangible knowledge is hypothesized to underlie a number of symptoms and features, and empirical testing is required. Such impairment of intangible knowledge can be tested with the property-listing paradigm and its variants, in which the participants' task is to list all the features they can for each presented item, or to rate the presence or influence of given features in each item (e.g., Taylor et al., 2007; Gainotti, 2012). Open-ended questions such as "What kind of person is Elizabeth?" (see Klin et al., 2007) may also be revealing about intangible knowledge deficits. To further examine the atypicality of visual scanpaths in ASD, the paradigm used by Gonzalez Andino and Grave de Peralta Menendez (2012), could be adapted for use with ASD and control presurgical patients, or eye tracking studies may be combined with investigation of prominent fixation regions in terms of salience, valence, and other intangible features. Impaired intangible knowledge is hypothesized to drive the preference for concrete cognition. An empirical prediction is that independent measures of abnormalities of intangible cognition and of concrete cognition should be inversely associated. Amygdala lesions in monkeys abolished the normal enhancement of visual cortex to emotional facial expressions (Hadj-Bouziane et al., 2012). It would be valuable to explore whether a corresponding impairment occurs in the auditory modality too, as this is a candidate mechanism for the apparent indifference to parents' voices, to own name being called, and to speech sounds in ASD. More generally, studies of sensory systems, amygdala, and PRC, and their involvement in intangible knowledge generation and representation, may facilitate advances in embodied cognition theory (see Varela et al., 1991; Chiel and Beer, 1997; Clark, 1999, 2008).

\section{CONCLUSION}

A hypothesis of an amygdala function that builds on and extends earlier proposals has now been presented, and makes several novel and substantial contributions to the literature. The hypothesis highlights the domain of intangible knowledge, 
which is an influential factor in social and other behaviors, but which has been little researched. The hypothesis elucidates the function that engages the likely heaviest of amygdala interconnections, and proposes it as a principal amygdala function. It has not received proportionate research attention. The hypothesis proposes that this amygdala function is the mediation of diverse, independent, meaningful, and fine-grained intangible knowledge representations; this differs from the few coarse-grained representations of relevance, salience, and so forth that are typically proposed. The formation of intangible knowledge representations and amygdala representations is not well understood. Evidence and hypotheses are set out on the formation of some of these representations. Amygdala's contribution to social cognition is unclear, following the monkey neonatal lesion experiments that refuted the proposal that amygdala mediates actual species-typical social behaviors (Bauman and Amaral, 2011). A novel answer to this open and important question is presented. On the basis of the main hypothesis, novel hypotheses are presented to explain several core ASD symptoms, which are currently poorly

\section{REFERENCES}

Abel, T. J., Rhone, A. E., Nourski, K. V., Kawasaki, H., Oya, H., Griffiths, T. D., et al. (2015). Direct physiological evidence of a heteromodal convergence region for proper naming in human left anterior temporal lobe. J. Neurosci. 35, 1513-1520. doi: 10.1523/JNEUROSCI.3387-14.2015

Adolphs, R. (2010). What does the amygdala contribute to social cognition? Ann. $N$ Y Acad. Sci. 1191, 42-61. doi: 10.1111/j.1749-6632.2010. 05445.x

Adolphs, R., Tranel, D., and Damasio, A. R. (1998). The human amygdala in social judgment. Nature 393, 470-474. doi: 10.1038/30982

Allport, D. A. (1985). "Distributed memory, modular subsystems and dysphasia," in Current Perspectives in Dysphasia, eds S. Newman and R. Epstein (Edinburgh: Churchill Livingstone), 32-60.

Amaral, D. G., and Price, J. L. (1984). Amygdalo-cortical projections in the monkey (Macaca fascicularis). J. Comp. Neurol. 230, 465-496. doi: 10.1002/cne. 902300402

Amaral, D. G., Dawson, G., and Geschwind, D. H. (2011). Autism Spectrum Disorders. New York, NY: Oxford University Press.

American Psychiatric Association. (1994). Diagnostic and Statistical Manual of Mental Disorders. 4th Edn. Washington, DC: American Psychiatric Association.

American Psychiatric Association. (2013). Diagnostic and Statistical Manual of Mental Disorders. 5th Edn. Washington, DC: American Psychiatric Association.

Anderson, A. K., and Phelps, E. A. (2001). Lesions of the human amygdala impair enhanced perception of emotionally salient events. Nature 411, 305-309. doi: 10.1038/35077083

Atkinson, A. P., and Adolphs, R. (2011). The neuropsychology of face perception: beyond simple dissociations and functional selectivity. Philos. Trans. R. Soc. Lond. B Biol. Sci. 366, 1726-1738. doi: 10.1098/rstb.2010.0349

Bachevalier, J. (1994). Medial temporal lobe structures and autism: a review of clinical and experimental findings. Neuropsychologia 32, 627-648. doi: 10.1016/0028-3932(94)90025-6

Baron-Cohen, S., Ring, H. A., Bullmore, E. T., Wheelwright, S., Ashwin, C., and Williams, S. C. (2000). The amygdala theory of autism. Neurosci. Biobehav. Rev. 24, 355-364. doi: 10.1016/s0149-7634(00)00011-7

Baron-Cohen, S., and Wheelwright, S. (1999). 'Obsessions' in children with autism or Asperger syndrome. Content analysis in terms of core domains of cognition. Br. J. Psychiatry 175, 484-490. doi: 10.1192/bjp.1 75.5.484

Barsalou, L. W. (2008). Grounded cognition. Annu. Rev. Psychol. 59, 617-645. doi: 10.1146/annurev.psych.59.103006.093639 understood, together with clear and specific proposals for empirical tests. This demonstrates the explanatory potential and broad significance of the main hypothesis. Taken together, the presented hypothesis should progress understanding of amygdala generally, of embodied cognition processes, of social processing, of clinical disorders with amygdala involvement, and is relevant for a comprehensive account of amygdala function.

\section{AUTHOR CONTRIBUTIONS}

The author confirms being the sole contributor of this work and approved it for publication.

\section{FUNDING}

This research did not receive any specific grant from funding agencies in the public, commercial, or not-for-profit sectors. It was self-funded.

Barsalou, L. W., Simmons, W. K., Barbey, A. K., and Wilson, C. D. (2003) Grounding conceptual knowledge in modality-specific systems. Trends Cogn. Sci. 7, 84-91. doi: 10.1016/s1364-6613(02)00029-3

Barton, R. A., and Aggleton, J. P. (2000). "Primate evolution and the amygdala," in The Amygdala: A Functional Analysis, 2nd Edn. ed. J. P. Aggleton (New York, NY: Oxford University Press), 479-508.

Bauman, M. D., and Amaral, D. G. (2011). "Nonhuman primate models of autism," in Autism Spectrum Disorders, eds D. G. Amaral, G. Dawson and D. H. Geschwind (New York, NY: Oxford University Press), 963-980.

Beauchamp, M. S. (2005). See me, hear me, touch me: multisensory integration in lateral occipital-temporal cortex. Curr. Opin. Neurobiol. 15, 145-153. doi: 10.1016/j.conb.2005.03.011

Behrens, T. E. J., and Johansen-Berg, H. (2005). Relating connectional architecture to grey matter function using diffusion imaging. Philos. Trans. R. Soc. Lond. B Biol. Sci. 360, 903-911. doi: 10.1098/rstb.2005.1640

Behrmann, M., Lee, A. C. H., Geskin, J. Z., Graham, K. S., and Barense, M. D. (2016). Temporal lobe contribution to perceptual function: a tale of three patient groups. Neuropsychologia 90, 33-45. doi: 10.1016/j.neuropsychologia. 2016.05.002

Bernard, J. F., Alden, M., and Besson, J. M. (1993). The organizationof the efferent projections from the pontine parabrachial area to the amygdaloid complex: a phaseolus vulgaris leucoagglutinin (PHAL-L) study in the rat. J. Comp. Neurol. 329, 201-229. doi: 10.1002/cne.903290205

Bernard, J. F., Bester, H., and Besson, J. M. (1995). "The spino-parabrachioamygdaloid and -hypothalamic nociceptive pathways," in Forebrain Areas involved in Pain Processing, eds J. M. Besson, G. Guilbaud and H. Ollat (Paris: John Libbey Eurotext), 27-48.

Beyeler, A., Namburi, P., Glober, G. F., Simonnet, C., Calhoon, G. G., Conyers, G. F., et al. (2016). Divergent routing of positive and negative information from the amygdala during memory retrieval. Neuron $90,348-361$. doi: 10.1016/j.neuron.2016.03.004

Bickart, K. C., Wright, C. I., Dautoff, R. J., Dickerson, B. C., and Barrett, L. F. (2011). Amygdala volume and social network size in humans. Nat. Neurosci. 14, 163-164. doi: 10.1038/nn.2724

Bingel, U., Lorenz, J., Schoell, E., Weiller, C., and Büchel, C. (2006). Mechanisms of placebo analgesia: rACC recruitment of a subcortical antinociceptive network. Pain 120, 8-15. doi: 10.1016/j.pain.2005.08.027

Bird, G. C., Lash, L. L., Han, J. S., Zou, X., Willis, W. D., and Neugebauer, V. (2005). Protein kinase A-dependent enhanced NMDA receptor function in pain-related synaptic plasticity in rat amygdala neurones. J. Physiol. 564 907-921. doi: 10.1113/jphysiol.2005.084780

Boes, A. D., Mehta, S., Rudrauf, D., Van Der Plas, E., Grabowski, T., Adolphs, R., et al. (2012). Changes in cortical morphology resulting from 
long-term amygdala damage. Soc. Cogn. Affect. Neurosci. 7, 588-595. doi: $10.1093 /$ scan/nsr047

Bouvier, S. E., and Engel, S. A. (2006). Behavioral deficits and cortical damage loci in cerebral achromatopsia. Cereb. Cortex 16, 183-191. doi: 10.1093/cercor/bhl065

Brannan, S., Liotti, M., Egan, G., Shade, R., Madden, L., Robillard, R., et al. (2001). Neuroimaging of cerebral activations and deactivations associated with hypercapnia and hunger for air. Proc. Natl. Acad. Sci. U S A 98, 2029-2034. doi: 10.1073/pnas.98.4.2029

Brashers-Krug, T., Shadmehr, R., and Bizzi, E. (1996). Consolidation in human motor memory. Nature 382, 252-255. doi: 10.1038/382252a0

Broman-Fulks, J. J., Ruggiero, K. J., Green, B. A., Kilpatrick, D. G., Danielson, C. K., Resnick, H. S., et al. (2006). Taxometric investigation of PTSD: data from two nationally representative samples. Behav. Ther. 37, 364-380. doi: 10.1016/j.beth.2006.02.006

Bzdok, D., Schilbach, L., Vogeley, K., Schneider, K., Laird, A. R., Langner, R., et al. (2012). Parsing the neural correlates of moral cognition: ALE meta-analysis on morality, theory of mind, and empathy. Brain Struct. Funct. 217, 783-796. doi: $10.1007 /$ s00429-012-0380-y

Cardin, V., Friston, K. J., and Zeki, S. (2011). Top-down modulations in the visual form pathway revealed with dynamic causal modeling. Cereb. Cortex 21, 550-562. doi: 10.1093/cercor/bhq122

Ceponiene, R., Lepisto, T., Shestakova, A., Vanhala, R., Alku, P., Naatanen, R., et al. (2003). Speech-sound-selective auditory impairment in children with autism: they can perceive but do not attend. Proc. Natl. Acad. Sci. U S A 100, 5567-5572. doi: 10.1073/pnas.0835631100

Cestari, V., Rossi-Arnaud, C., Saraulli, D., and Costanzi, M. (2014). The MAP(K) of fear: from memory consolidation to memory extinction. Brain Res. Bull. 105, 8-16. doi: 10.1016/j.brainresbull.2013.09.007

Chavez, C. M., McGaugh, J. L., and Weinberger, N. M. (2009). The basolateral amygdala modulates specific sensory memory representations in the cerebral cortex. Neurobiol. Learn. Mem. 91, 382-392. doi: 10.1016/j.nlm.2008.10.010

Chavez, C. M., McGaugh, J. L., and Weinberger, N. M. (2013). Activation of the basolateral amygdala induces long-term enhancement of specific memory representations in the cerebral cortex. Neurobiol. Learn. Mem. 101, 8-18. doi: 10.1016/j.nlm.2012.12.013

Chiel, H. J., and Beer, R. D. (1997). The brain has a body: adaptive behavior emerges from interactions of nervous system, body and environment. Trends Neurosci. 20, 553-557. doi: 10.1016/s0166-2236(97)01149-1

Chiou, R., and Lambon Ralph, M. A. (2016). The anterior temporal cortex is a primary semantic source of top-down influences on object recognition. Cortex 79, 75-86. doi: 10.1016/j.cortex.2016.03.007

Cikara, M., and Van Bavel, J. J. (2014). The neuroscience of intergroup relations: an integrative review. Perspect. Psychol. Sci. 9, 245-274. doi: $10.1177 / 1745691614527464$

Clark, A. (1999). An embodied cognitive science? Trends Cogn. Sci. 3, 345-351. doi: 10.1016/s1364-6613(99)01361-3

Clark, A. (2008). Supersizing the Mind: Embodiment, Action, and Cognitive Extension. New York, NY: Oxford University Press.

Clarke, A., Taylor, K. I., Devereux, B., Randall, B., and Tyler, L. K. (2013). From perception to conception: how meaningful objects are processed over time. Cereb. Cortex 23, 187-197. doi: 10.1093/cercor/bhs002

Clarke, A., and Tyler, L. K. (2014). Object-specific semantic coding in human perirhinal cortex. J. Neurosci. 34, 4766-4775. doi: 10.1523/JNEUROSCI.282813.2014

Conturo, T. E., Williams, D. L., Smith, C. D., Gultepe, E., Akbudak, E., and Minshew, N. J. (2008). Neuronal fibre pathway abnormalities in autism: an initial MRI diffusion tensor tracking study of hippocampo-fusiform and amygdalo-fusiform pathways. J. Int. Neuropsychol. Soc. 14, 933-946. doi: 10.1017/s1355617708081381

Cowell, R. A., Bussey, T. J., and Saksida, L. M. (2010). Components of recognition memory: dissociable cognitive processes or just differences in representational complexity? Hippocampus 20, 1245-1262. doi: 10.1002/hipo.20865

Craig, A. D. (2002). How do you feel? Interoception: the sense of the physiological condition of the body. Nat. Rev. Neurosci. 3, 655-666. doi: 10.1038/nrn894

Davies, R. R., Graham, K. S., Xuereb, J. H., Williams, G. B., and Hodges, J. R. (2004). The human perirhinal cortex and semantic memory. Eur. J. Neurosci. 20, 2441-2446. doi: 10.1111/j.1460-9568.2004.03710.x
Davis, M. (1992). The role of the amygdala in fear-potentiated startle: implications for animal models of anxiety. Trends Pharmacol. Sci. 13, 35-41. doi: 10.1016/0165-6147(92)90014-w

Demas, G. E., Williams, J. M., and Nelson, R. J. (1997). Amygdala but not hippocampal lesions impair olfactory memory for mate in prairie voles (Microtus ochrogaster). Am. J. Physiol. 273, R1683-R1689. doi: 10.1152/ajpregu.1997.273.5.r1683

Dubos, R. (1990). "Living with microbes," in The World of René Dubos: A Collection of his Writings, eds G. Piel and O. Segerberg (New York, NY: Henry Holt).

Duncan, A. W., and Bishop, S. L. (2015). Understanding the gap between cognitive abilities and daily living skills in adolescents with autism spectrum disorders with average intelligence. Autism 19, 64-72. doi: 10.1177/13623613135 10068

Eippert, F., Bingel, U., Schoell, E. D., Yacubian, J., Klinger, R., Lorenz, J., et al. (2009). Activation of the opioidergic descending pain control system underlies placebo analgesia. Neuron 63, 533-543. doi: 10.1016/j.neuron.2009.07.014

Eres, R., Louis, W. R., and Molenberghs, P. (2018). Common and distinct neural networks involved in fMRI studies investigating morality: an ALE metaanalysis. Soc. Neurosci. 13, 384-398. doi: 10.1080/17470919.2017.1357657

Evans, K. C., Banzett, R. B., Adams, L., McKay, L., Frackowiak, R. S. J., and Corfield, D. R. (2002). Bold fMRI identifies limbic, paralimbic and cerebellar activation during air hunger. J. Neurophysiol. 88, 1500-1511. doi: 10.1152/jn. 2002.88.3.1500

Ewbank, M. P., Barnard, P. J., Croucher, C. J., Ramponi, C., and Calder, A. J. (2009). The amygdala response to images with impact. Soc. Cogn. Affect. Neurosci. 4, 127-133. doi: 10.1093/scan/nsn048

Fanselow, M. S., and Kim, J. J. (1994). Acquisition of contextual pavlovian fear conditioning is blocked by application of an NMDA receptor antagonist D, L-2Amino-5-Phosphonovaleric acid to the basolateral amygdala. Behav. Neurosci. 108, 210-212. doi: 10.1037/0735-7044.108.1.210

Fanselow, M. S., and Wassum, K. M. (2016). The origins and organization of vertebrate Pavlovian conditioning. Cold Spring Harb. Perspect. Biol. 8:a021717. doi: 10.1101/cshperspect.a021717

Ferreira, G., Terrazas, A., Poindron, P., Nowak, R., Orgeur, P., and Lévy, F. (2000). Learning of olfactory cues is not necessary for early lamb recognition by the mother. Physiol. Behav. 69, 405-412. doi: 10.1016/s0031-9384(00) 00211-0

Fincham, F. D., and May, R. W. (2017). Infidelity in romantic relationships. Curr. Opin. Psychol. 13, 70-74. doi: 10.1016/j.copsyc.2016.03.008

Forbes, D., Haslam, N., Williams, B. J., and Creamer, M. (2005). Testing the latent structure of posttraumatic stress disorder: a taxometric study of combat veterans. J. Trauma. Stress 18, 647-656. doi: 10.1002/jts.20073

Fox, R. J., and Sorenson, C. A. (1994). Bilateral lesions of the amygdala attenuate analgesia induced by diverse environmental challenges. Brain Res. 648, 215-221. doi: 10.1016/0006-8993(94)91120-7

Frazier, T. W., Strauss, M., Klingemier, E. W., Zetzer, E. E., Hardan, A. Y., Eng, C., et al. (2017). A meta-analysis of gaze differences to social and nonsocial information between individuals with and without autism. J. Am. Acad. Child Adolesc. Psychiatry 56, 546-555. doi: 10.1016/j.jaac.2017.05.005

Freese, J. L., and Amaral, D. G. (2005). The organization of projections from the amygdala to visual cortical areas TE and VI in the macaque monkey. J. Comp. Neurol. 486, 295-317. doi: 10.1002/cne.20520

Freese, J. L., and Amaral, D. G. (2006). Synaptic organization of projections from the amygdala to visual cortical areas TE and VI in the macaque monkey. J. Comp. Neurol. 496, 655-667. doi: 10.1002/cne.20945

Freese, J. L., and Amaral, D. G. (2009). "Neuroanatomy of the primate amygdala," in The Human Amygdala, eds P. J. Whalen and E. A. Phelps (New York, NY: Guilford Press), 3-42.

Friedman, D. P., Murray, E. A., O’Neill, J. B., and Mishkin, M. (1986). Cortical connections of the somatosensory fields of the lateral sulcus of macaques: evidence for a corticolimbic pathway for touch. J. Comp. Neurol. 252, 323-347. doi: $10.1002 /$ cne. 902520304

Gainotti, G. (2012). The role of body-related and environmental sources of knowledge in the construction of different conceptual categories. Front. Psychol. 3:430. doi: 10.3389/fpsyg.2012.00430

Garrett, N., Lazzaro, S. C., Ariely, D., and Sharot, T. (2016). The brain adapts to dishonesty. Nat. Neurosci. 19, 1727-1732. doi: 10.1038/nn.4426 
Gauriau, C., and Bernard, J.-F. (2002). Pain pathways and parabrachial circuits in the rat. Exp. Physiol. 87, 251-258. doi: 10.1113/eph8702357

Gerbella, M., Baccarini, M., Borra, E., Rozzi, S., and Luppino, G. (2014). Amygdalar connections of the macaque areas 45A and 45B. Brain Struct. Funct. 219, 831-842. doi: 10.1007/s00429-013-0538-2

Gervais, H., Belin, P., Boddaert, N., Leboyer, M., Coez, A., Sfaello, I., et al. (2004). Abnormal cortical voice processing in autism. Nat. Neurosci. 7, 801-802. doi: $10.1038 / \mathrm{nn} 1291$

Geschwind, N. (1965). Disconnexion syndromes in animals and man. Brain 88, 237-294. doi: 10.1093/brain/88.2.237

Gilbertson, M. W., McFarlane, A. C., Weathers, F. W., Keane, T. M., Yehuda, R., Shalev, A. Y., et al. (2010). Is trauma a causal agent of psychopathologic symptoms in posttraumatic stress disorder? Findings from identical twins discordant for combat exposure. J. Clin. Psychiatry 71, 1324-1330. doi: 10.4088/jcp.10m06121blu

Gilligan, J. (2000). Violence: Reflections on Our Deadliest Epidemic. London: Jessica Kingsley Publishers.

Glanville, J. L., and Paxton, P. (2007). How do we learn to trust? A confirmatory tetrad analysis of the sources of generalized trust. Soc. Psychol. Q. 70, 230-242. doi: $10.1177 / 019027250707000303$

Gloor, P., Olivier, A., Quesney, L. F., Andermann, F., and Horowitz, S. (1982). The role of the limbic system in experiential phenomena of temporal lobe epilepsy. Ann. Neurol. 12, 129-144. doi: 10.1002/ana.410120203

Gómez-Robles, A., Hopkins, W. D., Schapiro, S. J., and Sherwood, C. C. (2015). Relaxed genetic control of cortical organization in human brains compared to chimpanzees. Proc. Natl. Acad. Sci. U S A 112, 14799-14804. doi: 10.1073/pnas. 1512646112

Gonzalez Andino, S. L., and Grave de Peralta Menendez, R. (2012). Coding saliency by ensemble bursting in the amygdala of primates. Front. Behav. Neurosci. 6:38. doi: 10.3389/fnbeh.2012.00038

Goosens, K. A., and Maren, S. (2004). NMDA receptors are essential for the acquisition, but not expression, of conditional fear and associative spike firing in the lateral amygdala. Eur. J. Neurosci. 20, 537-548. doi: 10.1111/j.1460-9568. 2004.03513.x

Gore, F., Schwartz, E. C., Brangers, B. C., Aladi, S., Stujenske, J. M., Likhtik, E., et al. (2015). Neural representations of unconditioned stimuli in basolateral amygdala mediate innate and learned responses. Cell 162, 134-145. doi: 10.1016/j.cell.2015.06.027

Gothard, K. M., Battaglia, F. P., Erickson, C. A., Spitler, K. M., and Amaral, D. G. (2007). Neural responses to facial expression and face identity in the monkey amygdala. J. Neurophysiol. 97, 1671-1683. doi: 10.1152/jn.007 14.2006

Gotts, S. J., Simmons, W. K., Milbury, L. A., Wallace, G. L., Cox, R. W., and Martin, A. (2012). Fractionation of social brain circuits in autism spectrum disorders. Brain 135, 2711-2725. doi: 10.1093/brain/aws160

Grandin, T. (2005). "A personal perspective of autism," in Handbook of Autism and Pervasive Developmental Disorders, 3rd Edn. eds F. R. Volkmar, R. Paul, A. Klin and D. Cohen (New York, NY: John Wiley \& Sons), 1276-1286.

Grayson, D. S., Bliss-Moreau, E., Bennett, J., Lavenex, P., and Amaral, D. G. (2017). Neural reorganization due to neonatal amygdala lesions in the rhesus monkey: changes in morphology and network structure. Cereb. Cortex 27, 3240-3253. doi: 10.1093/cercor/bhx080

Green, J., Gilchrist, A., Burton, D., and Cox, A. (2000). Social and psychiatric functioning in adolescents with Asperger syndrome compared with conduct disorder. J. Autism Dev. Disord. 30, 279-293. doi: 10.1023/A:1005523232106

Grelotti, D. J., Klin, A. J., Gauthier, I., Skudlarski, P., Cohen, D. J., and Gore, J. C. (2005). fMRI activation of the fusiform gyrus and amygdala to cartoon characters but not to faces in a boy with autism. Neuropsychologia 43, 373-385. doi: 10.1016/j.neuropsychologia.2004.06.015

Guassi Moreira, J. F., Van Bavel, J. J., and Telzer, E. H. (2017). The neural development of 'us and them'. Soc. Cogn. Affect. Neurosci. 12, 184-196. doi: $10.1093 / \mathrm{scan} / \mathrm{nsw} 134$

Gur, R., Tendler, A., and Wagner, S. (2014). Long-term social recognition memory is mediated by oxytocin-dependent synaptic plasticity in the medial amygdala. Biol. Psychiatry 76, 377-386. doi: 10.1016/j.biopsych.2014.03.022

Hadj-Bouziane, F., Liu, N., Bell, A. H., Gothard, K. M., Luh, W.-M., Tootell, R. B. H., et al. (2012). Amygdala lesions disrupt modulation of functional MRI activity evoked by facial expression in the monkey inferior temporal cortex. Proc. Natl. Acad. Sci. U S A 109, E3640-E3648. doi: 10.1073/pnas.1218406109

Hamann, S. (2009). "The human amygdala and memory," in The Human Amygdala, eds P. J. Whalen and E. A. Phelps (New York, NY: Guilford Press), 177-203.

Hare, B. (2017). Survival of the friendliest: homo sapiens evolved via selection for prosociality. Annu. Rev. Psychol. 68, 155-186. doi: 10.1146/annurev-psych010416-044201

Haxby, J. V., Gobbini, M. I., and Montgomery, K. (2004). "Spatial and temporal distribution of face and object representations in the human brain," in The Cognitive Neurosciences, 3rd Edn. ed. M. S. Gazzaniga (Cambridge, MA: MIT Press), 889-904.

Hegdé, J. (2008). Time course of visual perception: coarse-to-fine processing and beyond. Prog. Neurobiol. 84, 405-439. doi: 10.1016/j.pneurobio.2007. 09.001

Helmstetter, F. J., Tershner, S. A., Poore, L. H., and Bellgowan, P. S. F. (1998). Antinociception following opioid stimulation of the basolateral amygdala is expressed through the periacqueductal gray and rostral ventromedial medulla. Brain Res. 779, 104-118. doi: 10.1016/s0006-8993(97) 01104-9

Hernádi, I., Grabenhorst, F., and Schultz, W. (2015). Planning activity for internally generated reward goals in monkey amygdala neurons. Nat. Neurosci. 18, 461-469. doi: 10.1038/nn.3925

Hoffman, P., Evans, G. A. L., and Lambon Ralph, M. A. (2014). The anterior temporal lobes are critically involved in acquiring new conceptual knowledge: evidence for impaired feature integration in semantic dementia. Cortex 50, 19-31. doi: 10.1016/j.cortex.2013.10.006

Howlin, P., Moss, P., Savage, S., and Rutter, M. (2013). Social outcomes in midto later adulthood among individuals diagnosed with autism and average nonverbal IQ as children. J. Am. Acad. Child Adolesc. Psychiatry 52, 572-581. doi: 10.1016/j.jaac.2013.02.017

Ikeda, R., Takahashi, Y., Inoue, K., and Kato, F. (2007). NMDA receptorindependent synaptic plasticity in the central amygdala in the rat model of neuropathic pain. Pain 127, 161-172. doi: 10.1016/j.pain.2006. 09.003

Iwai, E., and Yukie, M. (1987). Amygdalofugal and amygdalopetal connections with modality-specific visual cortical areas in macaques (Macaca fuscata, M. mulatta, and M. fascicularis). J. Comp. Neurol. 261, 362-387. doi: $10.1002 /$ cne. 902610304

Janak, P. H., and Tye, K. M. (2015). From circuits to behaviour in the amygdala. Nature 517, 284-292. doi: 10.1038/nature14188

Jemel, B., Mottron, L., and Dawson, M. (2006). Impaired face processing in autism: fact or artifact? Int. J. Comput. Assist. Radiol. Surg. 36, 91-106. doi: 10.1007/s10803-005-0050-5

Jolliffe, T., Lansdown, R., and Robinson, C. (1992). Autism: a personal account. Communication 26, 12-19.

Kadohisa, M., Verhagen, J. V., and Rolls, E. T. (2005). The primate amygdala: neuronal representations of the viscosity, fat texture, temperature, grittiness and taste of foods. Neuroscience 132, 33-48. doi: 10.1016/j.neuroscience.2004. 12.005

Kanner, L. (1943). Autistic disturbances of affective contact. Nervous Child 2, $217-250$.

Kapur, N. (1996). Paradoxical functional facilitation in brain-behaviour research. Brain 119, 1775-1790. doi: 10.1093/brain/119.5.1775

Karni, A., Meyer, G., Rey-Hipolito, C., Jezzard, P., Adams, M. M., Turner, R., et al. (1998). The acquisition of skilled motor performance: fast and slow experiencedriven changes in primary motor cortex. Proc. Natl. Acad. Sci. U S A 95, 861-868. doi: 10.1073/pnas.95.3.861

Kavaliers, M., Colwell, D. D., Choleris, E., and Ossenkopp, K.-P. (1999). Learning to cope with biting flies: rapid NMDA-mediated acquisition of conditioned analgesia. Behav. Neurosci. 113, 126-135. doi: 10.1037//0735-7044.113.1.126

Keller, M., Perrin, G., Meurisse, M., Ferreira, G., and Lévy, F. (2004). Cortical and medial amygdala are both involved in the formation of olfactory offspring memory in sheep. Eur. J. Neurosci. 20, 3433-3441. doi: 10.1111/j.1460-9568. 2004.03812.x

Kim, J. E., Lyoo, I. K., Estes, A. M., Renshaw, P. F., Shaw, D. W., Friedman, S. D., et al. (2010). Laterobasal amygdalar enlargement in 6- to 7-year old 
children with autism spectrum disorder. Arch. Gen. Psychiatry 67, 1187-1197. doi: 10.1001/archgenpsychiatry.2010.148

Kleinhans, N. M., Richards, T., Johnson, L. C., Weaver, K. E., Greenson, J., Dawson, G., et al. (2011). fMRI evidence of neural abnormalities in the subcortical face processing system in ASD. Neuroimage 54, 697-704. doi: 10.1016/j.neuroimage.2010.07.037

Kleinhans, N. M., Richards, T., Sterling, L., Stegbauer, K. C., Mahurin, R., Johnson, L. C., et al. (2008). Abnormal functional connectivity in autism spectrum disorders during face processing. Brain 131, 1000-1012. doi: 10.1093/brain/awm334

Klin, A. (1991). Young autistic children's listening preferences in regard to speech: a possible characterization of the symptom of social withdrawal. J. Autism Dev. Disord. 21, 29-42. doi: 10.1007/bf02206995

Klin, A., Danovitch, J. H., Merz, A. B., and Volkmar, F. R. (2007). Circumscribed interests in higher functioning individuals with autism spectrum disorders: an exploratory study. Res. Pract. Persons Severe Disabl. 32, 89-100. doi: $10.2511 /$ rpsd.32.2.89

Klin, A., and Jones, W. (2006). Attributing social and physical meaning to ambiguous visual displays in individuals with higher-functioning autism spectrum disorders. Brain Cogn. 61, 40-53. doi: 10.1016/j.bandc.2005.12.016

Klin, A., Jones, W., Schultz, R., and Volkmar, F. (2003). The enactive mind, or from actions to cognition: lessons from autism. Philos. Trans. R. Soc. Lond. B Biol. Sci. 358, 345-360. doi: 10.1098/rstb.2002.1202

Klin, A., Jones, W., Schultz, R., Volkmar, F., and Cohen, D. (2002). Visual fixation patterns during viewing of naturalistic social situations as predictors of social competence in individuals with autism. Arch. Gen. Psychiatry 59, 809-816. doi: 10.1001/archpsyc.59.9.809

Klin, A., Lin, D. J., Gorrindo, P., Ramsay, G., and Jones, W. (2009). Two-year-olds with autism orient to non-social contingencies rather than biological motion. Nature 459, 257-261. doi: 10.1038/nature07868

Knuepfer, M. M., Eismann, A., Schütze, I., Stumpf, H., and Stock, G. (1995). Responses of single neurons in amygdala to interoceptive and exteroceptive stimuli in conscious cats. Am. J. Physiol. 268, R666-R675. doi: 10.1152/ajpregu. 1995.268.3.r666

Koelsch, S., and Skouras, S. (2014). Functional centrality of amygdala, striatum and hypothalamus in a "small world" network underlying joy: an fMRI study with music. Hum. Brain Mapp. 35, 3485-3498. doi: 10.1002/hbm. 22416

Koelsch, S., Skouras, S., Fritz, T., Herrera, P., Bonhage, C., Küssner, M. B., et al. (2013). The roles of superficial amygdala and auditory cortex in music-evoked fear and joy. Neuroimage 81, 49-60. doi: 10.1016/j.neuroimage.2013.05.008

Koenigs, M., Huey, E. D., Raymont, V., Cheon, B., Solomon, J., Wassermann, E. M., et al. (2008). Focal brain damage protects against post-traumatic stress disorder in combat veterans. Nat. Neurosci. 11, 232-237. doi: $10.1038 / \mathrm{nn} 2032$

Koscik, T. R., and Tranel, D. (2011). The human amygdala is necessary for developing and expressing normal interpersonal trust. Neuropsychologia 49, 602-611. doi: 10.1016/j.neuropsychologia.2010.09.023

Kravitz, D. J., Saleem, K. S., Baker, C. I., Ungerleider, L. G., and Mishkin, M. (2013). The ventral visual pathway: an expanded neural framework for the processing of object quality. Trends Cogn. Sci. 17, 26-49. doi: 10.1016/j.tics.2012. 10.011

Kringelbach, M. L., and Rolls, E. T. (2004). The functional neuroanatomy of the human orbitofrontal cortex: evidence from neuroimaging and neuropsychology. Prog. Neurobiol. 72, 341-372. doi: 10.1016/s03010082(04)00039-5

Ku, S.-P., Tolias, A. S., Logothetis, N. K., and Goense, J. (2011). fMRI of the face-processing network in the ventral temporal lobe of awake and anesthetized macaques. Neuron 70, 352-362. doi: 10.1016/j.neuron.2011.02.048

Kumar, S., von Kriegstein, K., Friston, K., and Griffiths, T. D. (2012). Features versus feelings: dissociable representations of the acoustic features and valence of aversive sounds. J. Neurosci. 32, 14184-14192. doi: 10.1523/JNEUROSCI. $1759-12.2012$

Kumaran, D., Banino, A., Blundell, C., Hassabis, D., and Dayan, P. (2016). Computations underlying social hierarchy learning: distinct neural mechanisms for updating and representing self-relevant information. Neuron 92, 1135-1147. doi: 10.1016/j.neuron.2016.10.052
Kumaran, D., Melo, H. L., and Duzel, E. (2012). The emergence and representation of knowledge about social and nonsocial hierarchies. Neuron 76, 653-666. doi: 10.1016/j.neuron.2012.09.035

LaBar, K. S., and Warren, L. H. (2009). "Methodological approaches to studying the human amygdala," in The Human Amygdala, eds P. J. Whalen and E. A. Phelps (New York, NY: Guilford Press), 155-176.

Laberge, F., Mühlenbrock-Lenter, S., Grunwald, W., and Roth, G. (2006). Evolution of the amygdala: new insights from studies in amphibians. Brain Behav. Evol. 67, 177-187. doi: 10.1159/000091119

Laing, M., and Bashir, Z. I. (2014). B-adrenoreceptors and synaptic plasticity in the perirhinal cortex. Neuroscience 273, 163-173. doi: 10.1016/j.neuroscience.2014. 04.070

Lavner, J. A., and Bradbury, T. N. (2012). Why do even satisfied newlyweds eventually go on to divorce? J. Fam. Psychol. 26, 1-10. doi: 10.1037/a0025966

Lawrie, S. M. (2017). Parsing heterogeneity. JAMA Psychiatry 74, 1089-1090. doi: 10.1001/jamapsychiatry.2017.2953

LeDoux, J. E. (2014). Coming to terms with fear. Proc. Natl. Acad. Sci. U S A 111, 2871-2878. doi: 10.1073/pnas.1400335111

Lee, A. C. H., Buckley, M. J., Gaffan, D., Emery, T., Hodges, J. R., and Graham, K. S. (2006). Differentiating the roles of the hippocampus and perirhinal cortex in processes beyond long-term declarative memory: a double dissociation in dementia. J. Neurosci. 26, 5198-5203. doi: 10.1523/JNEUROSCI.3157-05.2006

Lee, A. C. H., Bussey, T. J., Murray, E. A., Saksida, L. M., Epstein, R. A., Kapur, N., et al. (2005). Perceptual deficits in amnesia: challenging the medial temporal lobe 'mnemonic' view. Neuropsychologia 43, 1-11. doi: 10.1016/j. neuropsychologia.2004.07.017

Lepistö, T., Kujala, T., Vanhala, R., Alku, P., Huotilainen, M., and Näätänen, R. (2005). The discrimination of and orienting to speech and non-speech sounds in children with autism. Brain Res. 1066, 147-157. doi: 10.1016/j.brainres.2005. 10.052

Lévy, F., Locatelli, A., Piketty, V., Tillet, Y., and Poindron, P. (1995). Involvement of the main but not the accessory olfactory system in maternal behavior of primiparous and multiparous ewes. Physiol. Behav. 57, 97-104. doi: 10.1016/0031-9384(94)00200-o

Li, H., Penzo, M. A., Taniguchi, H., Kopec, C. D., Huang, Z. J., and Li, B. (2013). Experience-dependent modification of a central amygdala fear circuit. Nat Neurosci. 16, 332-339. doi: 10.1038/nn.3322

Liotti, M., Brannan, S., Egan, G., Shade, R., Madden, L., Abplanalp, B., et al. (2001). Brain responses associated with consciousness of breathlessness (air hunger). Proc. Natl. Acad. Sci. U S A 98, 2035-2040. doi: 10.1073/pnas.98. 4.2035

Loewy, A. D. (1990). "Anatomy of the autonomic nervous system: an overview," in Central Regulation of Autonomic Functions, eds A. D. Loewy and K. M. Spyer (New York, NY: Oxford University Press), 3-16.

Machado, C. J., and Bachevalier, J. (2003). Non-human primate models of childhood psychopathology: the promise and the limitations. J. Child Psychol. Psychiatry 44, 64-87. doi: 10.1111/1469-7610.00103

Machado, C. J., and Bachevalier, J. (2007). The effects of selective amygdala, orbital frontal cortex or hippocampal formation lesions on reward assessment in non-human primates. Eur. J. Neurosci. 25, 2885-2904. doi: 10.1111/j.14609568.2007.05525.x

Maire, J. J., Close, L. N., Heinricher, M. M., and Selden, N. R. (2016). Distinct pathways for norepinephrine- and opioid-triggered antinociception from the amygdala. Eur. J. Pain 20, 206-214. doi: 10.1002/ejp.708

Manning, B. H., Martin, W. J., and Meng, I. D. (2003). The rodent amygdala contributes to the production of cannabinoid-induced antinociception. Neuroscience 120, 1157-1170. doi: 10.1016/s0306-4522(03) 00356-7

Manning, B. H., Merin, N. M., Meng, I. D., and Amaral, D. G. (2001). Reduction in opioid- and cannabinoid-induced antinociception in rhesus monkeys after bilateral lesions of the amygdaloid complex. J. Neurosci. 21, 8238-8246. doi: 10.1523/JNEUROSCI.21-20-08238.2001

Maquet, P. (2001). The role of sleep in learning and memory. Science 294, 1048-1052. doi: $10.1126 /$ science. 1062856

Martin, A. (2009). "Circuits in mind: the neural foundations for object concepts," in The Cognitive Neurosciences, 4th Edn. ed. M. S. Gazzaniga (Cambridge, MA: MIT Press), 1031-1045. 
Martin, A. (2016). GRAPES-Grounding representations in action, perception, and emotion systems: how object properties and categories are represented in the human brain. Psychon. Bull. Rev. 23, 979-990. doi: 10.3758/s13423-015 $-0842-3$

Mayberg, H. S. (2009). Target electrode-based modulation of neural circuits for depression. J. Clin. Invest. 119, 717-725. doi: 10.1172/jci38454

Mazzola, L., Isnard, J., and Mauguière, F. (2006). Somatosensory and pain responses to stimulation of the second somatosensory area (SII) in humans. A comparison with SI and insular responses. Cereb. Cortex 16, 960-968. doi: $10.1093 /$ cercor/bhj038

McDonald, A. J. (1998). Cortical pathways to the mammalian amygdala. Prog. Neurobiol. 55, 257-332. doi: 10.1016/s0301-0082(98)00003-3

McGaugh, J. L. (2004). The amygdala modulates the consolidation of memories of emotionally arousing experiences. Annu. Rev. Neurosci. 27, 1-28. doi: 10.1146/annurev.neuro.27.070203.144157

McGaugh, J. L. (2013). Making lasting memories: remembering the significant. Proc. Natl. Acad. Sci. U S A 110, 10402-10407. doi: 10.1073/pnas.1301209110

McIntyre, C. K., McGaugh, J. L., and Williams, C. L. (2012). Interacting brain systems modulate memory consolidation. Neurosci. Biobehav. Rev. 36, 1750-1762. doi: 10.1016/j.neubiorev.2011.11.001

Mende-Siedlecki, P., Said, C. P., and Todorov, A. (2013). The social evaluation of faces: a meta-analysis of functional neuroimaging studies. Soc. Cogn. Affect. Neurosci. 8, 285-299. doi: 10.1093/scan/nsr090

Meyer, K., and Damasio, A. (2009). Convergence and divergence in a neural architecture for recognition and memory. Trends Neurosci. 32, 376-382. doi: $10.1016 /$ j.tins.2009.04.002

Midorikawa, A., and Kawamura, M. (2015). The emergence of artistic ability following traumatic brain injury. Neurocase 21, 90-94. doi: 10.1080/13554794. 2013.873058

Miller, B. L., Boone, K., Cummings, J. L., Read, S. L., and Mishkin, F. (2000), Functional correlates of musical and visual ability in frontotemporal dementia. Br. J. Psychiatry 176, 458-463. doi: 10.1192/bjp.176.5.458

Miller, B. L., Cummings, J., Mishkin, F., Boone, K., Prince, F., Ponton, M., et al. (1998). Emergence of artistic talent in frontotemporal dementia. Neurology 51, 978-982. doi: 10.1212/WNL.51.4.978

Miller, M., Iosif, A.-M., Hill, M., Young, G. S., Schwichtenberg, A. J., and Ozonoff, S. (2017). Response to name in infants developing autism spectrum disorder: a prospective study. J. Pediatr. 183, 141-146. doi: 10.1016/j.jpeds. 2016.12.071

Minxha, J., Mosher, C., Morrow, J. K., Mamelak, A. N., Adolphs, R., Gothard, K. M., et al. (2017). Fixations gate species-specific responses to free viewing of faces in the human and macaque amygdala. Cell Rep. 18, 878-891. doi: 10.1016/j.celrep.2016.12.083

Moadab, G., Bliss-Moreau, E., and Amaral, D. G. (2015). Adult social behavior with familiar partners following neonatal amygdala or hippocampus damage. Behav. Neurosci. 129, 339-350. doi: 10.1037/bne0000062

Mollo, G., Cornelissen, P. L., Millman, R. E., Ellis, A. W., and Jefferies, E. (2017). Oscillatory dynamics supporting semantic cognition: MEG evidence for the contribution of the anterior temporal lobe hub and modality-specific spokes. PLoS One 12:e0169269. doi: 10.1371/journal.pone.01 69269

Mosher, C. P., Zimmerman, P. E., Fuglevand, A. J., and Gothard, K. M. (2016). Tactile stimulation of the face and the production of facial expressions activate neurons in the primate amygdala. eNeuro 3:ENEURO.0182-16.2016. doi: 10.1523/ENEURO.0182-16.2016

Mundy, M. E., Downing, P. E., Dwyer, D. M., Honey, R. C., and Graham, K. S. (2013). A critical role for the hippocampus and perirhinal cortex in perceptual learning of scenes and faces: complementary findings from amnesia and fMRI. J. Neurosci. 33, 10490-10502. doi: 10.1523/JNEUROSCI.2958 $-12.2013$

Munson, J., Dawson, G., Abbott, R., Faja, S., Webb, S. J., Friedman, S. D., et al. (2006). Amygdalar volume and behavioral development in autism. Arch. Gen. Psychiatry 63, 686-693. doi: 10.1001/archpsyc.63.6.686

Murray, E. A., Izquierdo, A., and Malkova, L. (2009). "Amygdala function in positive reinforcement," in The Human Amygdala, eds P. J. Whalen and E. A. Phelps (New York, NY: Guilford Press), 82-104.

Murray, E. A., and Rudebeck, P. H. (2013). The drive to strive: goal generation based on current needs. Front. Neurosci. 7:112. doi: 10.3389/fnins.2013.00112
Murty, V. P., Ritchey, M., Adcock, R. A., and LaBar, K. S. (2010). fMRI studies of successful emotional memory encoding: a quantitative meta-analysis. Neuropsychologia 48, 3459-3469. doi: 10.1016/j.neuropsychologia.2010. 07.030

Nacewicz, B. M., Dalton, K. M., Johnstone, T., Long, M. T., McAuliff, E. M., Oakes, T. R., et al. (2006). Amygdala volume and nonverbal social impairment in adolescent and adult males with autism. Arch. Gen. Psychiatry 63, 1417-1428. doi: $10.1001 /$ archpsyc.63.12.1417

Naci, L., Taylor, K. I., Cusack, R., and Tyler, L. K. (2012). Are the senses enough for sense? Early high-level feedback shapes our comprehension of multisensory objects. Front. Integr. Neurosci. 6:82. doi: 10.3389/fnint.2012.00082

Nadel, L., and Hardt, O. (2011). Update on memory systems and processes. Neuropsychopharmacology 36, 251-273. doi: 10.1038/npp.2010.169

Nadig, A. S., Ozonoff, S., Young, G. S., Rozga, A., Sigman, M., and Rogers, S. J. (2007). A prospective study of response to name in infants at risk for autism. Arch. Pediatr. Adolesc. Med. 161, 378-383. doi: 10.1001/archpedi.161.4.378

Neugebauer, V. (2015). Amygdala pain mechanisms. Handb. Exp. Pharmacol. 227, 261-284. doi: 10.1007/978-3-662-46450-2_13

Neugebauer, V., Li, W., Bird, G. C., Bhave, G., and Gereau, R. W. IV. (2003). Synaptic plasticity in the amygdala in a model of arthritic pain: differential roles of metabotropic glutamate receptors 1 and 5. J. Neurosci 23, 52-63. doi: 10.1523/JNEUROSCI.23-01-00052.2003

Niu, Y., Todd, R. M., and Anderson, A. K. (2012). Affective salience can reverse the effects of stimulus-driven salience on eye movements in complex scenes. Front. Psychol. 3:336. doi: 10.3389/fpsyg.2012.00336

Noonan, M. P., Sallet, J., Mars, R. B., Neubert, F. X., O’Reilly, J. X., Andersson, J. L., et al. (2014). A neural circuit covarying with social hierarchy in macaques. PLoS Biol. 12:e1001940. doi: 10.1371/journal.pbio.1001940

O’Doherty, J., Rolls, E. T., Francis, S., Bowtell, R., McGlone, F., Kobal, G., et al. (2000). Sensory-specific satiety-related olfactory activation of the human orbitofrontal cortex. Neuroreport 11, 893-897. doi: 10.1097/00001756200003200-00046

Oi, H., Hashimoto, T., Nozawa, T., Kanno, A., Kawata, N., Hirano, K., et al. (2017). Neural correlates of ambient thermal sensation: an fMRI study. Sci. Rep. 7:11279. doi: 10.1038/s41598-017-11802-z

Omigie, D., Dellacherie, D., Hasboun, D., Clément, S., Baulac, M., Adam, C., et al. (2015a). Intracranial markers of emotional valence processing and judgements in music. Cogn. Neurosci. 6, 16-23. doi: 10.1080/17588928.2014. 988131

Omigie, D., Dellacherie, D., Hasboun, D., George, N., Clément, S., Baulac, M., et al. (2015b). An intracranial EEG study of the neural dynamics of musical valence processing. Cereb. Cortex 25, 4038-4047. doi: 10.1093/cercor/bhu118

Ostrowsky, K., Isnard, J., Ryvlin, P., Guénot, M., Fischer, C., and Mauguière, F. (2000). Functional mapping of the insular cortex: clinical implication in temporal lobe epilepsy. Epilepsia 41, 681-686. doi: 10.1111/j.1528-1157.2000. tb00228.x

Oxford English Dictionary Online. (1989). Important. [Accessed March 31, 2010].

Passingham, R. E., and Wise, S. P. (2012). The Neurobiology of the Prefrontal Cortex: Anatomy, Evolution, and the Origin of Insight. Oxford: Oxford University Press.

Patin, A., and Pause, B. M. (2015). Human amygdala activations during nasal chemoreception. Neuropsychologia 78, 171-194. doi: 10.1016/j. neuropsychologia.2015.10.009

Paton, J. J., Belova, M. A., Morrison, S. E., and Salzman, C. D. (2006). The primate amygdala represents the positive and negative value of visual stimuli during learning. Nature 439, 865-870. doi: 10.1038/nature04490

Patriquin, M. A., DeRamus, T., Libero, L. E., Laird, A., and Kana, R. K. (2016), Neuroanatomical and neurofunctional markers of social cognition in autism spectrum disorder. Hum. Brain Mapp. 37, 3957-3978. doi: 10.1002/hbm. 23288

Pelphrey, K. A., Morris, J. P., Michelich, C. R., Allison, T., and McCarthy, G. (2005). Functional anatomy of biological motion perception in posterior temporal cortex: an fMRI study of eye, mouth and hand movements. Cereb. Cortex 15, 1866-1876. doi: 10.1093/cercor/bhi064

Perlman, S. B., Hudac, C. M., Pegors, T., Minshew, N. J., and Pelphrey, K. A. (2011). Experimental manipulation of face-evoked activity in the fusiform gyrus of individuals with autism. Soc. Neurosci. 6, 22-30. doi: $10.1080 / 17470911003683185$ 
Perrodin, C., Kayser, C., Abel, T. J., Logothetis, N. K., and Petkov, C. I. (2015). Who is that? Brain networks and mechanisms for identifying individuals. Trends Cogn. Sci. 19, 783-796. doi: 10.1016/j.tics.2015.09.002

Perugini, A., Laing, M., Berretta, N., Aicardi, G., and Bashir, Z. I. (2012). Synaptic plasticity from amygdala to perirhinal cortex: a possible mechanism for emotional enhancement of visual recognition memory. Eur. J. Neurosci. 36, 2421-2427. doi: 10.1111/j.1460-9568.2012.08146.x

Pessoa, L., and Adolphs, R. (2010). Emotion processing and the amygdala: from a 'low road' to 'many roads' of evaluating biological significance. Nat. Rev. Neurosci. 11, 773-782. doi: 10.1038/nrn2920

Petrulis, A. (2009). Neural mechanisms of individual and sexual recognition in Syrian hamsters (Mesocricetus auratus). Behav. Brain Res. 200, 260-267. doi: 10.1016/j.bbr.2008.10.027

Phelps, E. A. (2009). "The human amygdala and the control of fear," in The Human Amygdala, eds P. J. Whalen and E. A. Phelps (New York, NY: Guilford Press), 204-219.

Piech, R. M., Lewis, J., Parkinson, C. H., Owen, A. M., Roberts, A. C., Downing, P. E., et al. (2009). Neural correlates of appetite and hunger-related evaluative judgements. PLoS One 4:e6581. doi: 10.1371/journal.pone.0006581

Pierce, K., and Redcay, E. (2008). Fusiform function in children with an autism spectrum disorder is a matter of "who". Biol. Psychiatry 64, 552-560. doi: 10.1016/j.biopsych.2008.05.013

Pitkänen, A. (2000). "Connectivity of the rat amygdaloid complex," in The Amygdala: A Functional Analysis, 2nd Edn. ed. J. P. Aggleton (New York, NY: Oxford University Press), 31-115.

Platt, M. L., Seyfarth, R. M., and Cheney, D. L. (2016). Adaptions for social cognition in the primate brain. Philos. Trans. R. Soc. Lond. B Biol. Sci. 371:20150096. doi: 10.1098/rstb.2015.0096

Prather, M. D., Lavenex, P., Mauldin-Jourdain, M. L., Mason, W. A., Capitanio, J. P., Mendoza, S. P., et al. (2001). Increased social fear and decreased fear of objects in monkeys with neonatal amygdala lesions. Neuroscience 106, 653-658. doi: 10.1016/s0306-4522(01)00445-6

Price, J. L. (2006). "Connections of orbital cortex," in The Orbitofrontal Cortex, eds D. H. Zald and S. L. Rauch (New York, NY: Oxford University Press), 39-55.

Price, J. L., and Drevets, W. C. (2012). Neural circuits underlying the pathophysiology of mood disorders. Trends Cogn. Sci. 16, 61-71. doi: 10.1016/j. tics.2011.12.011

Pritchard, T. C., and Norgren, R. (2004). "Gustatory system," in The Human Nervous System, 2nd Edn. eds G. Paxinos and J. K. Mai (Amsterdam: Elsevier Academic), 1171-1196.

Rachman, S. (2010). Betrayal: a psychological analysis. Behav. Res. Ther. 48, 304-311. doi: 10.1016/j.brat.2009.12.002

Rapin, I. (2006). "Atypical sensory/perceptual responsiveness," in Autism: A Neurological Disorder of Early Brain Development, eds R. Tuchman and I. Rapin (London: Mac Keith Press), 202-230.

Reynolds, J., and Mansfield, P. (1999). "The effect of changing attitudes to marriage on its stability," in High Divorce Rates: The State of the Evidence on Reasons and Remedies. Research Series No. 2/99, ed. J. Simons (London: Lord Chancellor's Department), 1-46.

Rolls, E. T. (2000). Functions of the primate temporal lobe cortical visual areas in invariant visual object and face recognition. Neuron 27, 205-218. doi: 10.1016/s0896-6273(00)00030-1

Rolls, E. T. (2005). Taste, olfactory, and food texture processing in the brain and the control of food intake. Physiol. Behav. 85, 45-56. doi: 10.1016/j.physbeh. 2005.04.012

Roozendaal, B., Quirarte, G. L., and McGaugh, J. L. (1997). Stress-activated hormonal systems and the regulation of memory storage. Ann. N Y Acad. Sci. 821, 247-258. doi: 10.1111/j.1749-6632.1997.tb48284.x

Ropar, D., and Peebles, D. (2007). Sorting preference in children with autism: the dominance of concrete features. J. Autism Dev. Disord. 37, 270-280. doi: 10.1007/s10803-006-0166-2

Rossion, B., Caldara, R., Seghier, M., Schuller, A.-M., Lazeyras, F., and Mayer, E. (2003). A network of occipito-temporal face-sensitive areas besides the right middle fusiform gyrus is necessary for normal face processing. Brain 126, 2381-2395. doi: 10.1093/brain/awg241

Rossion, B., Hanseeuw, B., and Dricot, L. (2012). Defining face perception areas in the human brain: a large-scale factorial fMRI face localizer analysis. Brain Cogn. 79, 138-157. doi: 10.1016/j.bandc.2012.01.001
Rouwette, T., Vanelderen, P., Roubos, E. W., Kozicz, T., and Vissers, K. (2012). The amygdala, a relay station for switching on and off pain. Eur. J. Pain 16, 782-792. doi: 10.1002/j.1532-2149.2011.00071.x

Rudebeck, P. H., and Murray, E. A. (2011). Balkanizing the primate orbitofrontal cortex: distinct subregions for comparing and contrasting values. Ann. N Y Acad. Sci. 1239, 1-13. doi: 10.1111/j.1749-6632.2011.06267.x

Ruscio, A. M., Ruscio, J., and Keane, T. M. (2002). The latent structure of posttraumatic stress disorder: a taxometric investigation of reactions to extreme stress. J. Abnorm. Psychol. 111, 290-301. doi: 10.1037/0021-843x.111.2.290

Rutishauser, U., Mamelak, A. N., and Adolphs, R. (2015). The primate amygdala in social perception-insights from electrophysiological recordings and stimulation. Trends Neurosci. 38, 295-306. doi: 10.1016/j.tins.2015. 03.001

Rutishauser, U., Tudusciuc, O., Wang, S., Mamelak, A. N., Ross, I. B., and Adolphs, R. (2013). Single-neuron correlates of atypical face processing in autism. Neuron 80, 887-899. doi: 10.1016/j.neuron.2013.08.029

Saker, P., Farrell, M. J., Egan, G. F., McKinley, M. J., and Denton, D. A. (2018). Influence of anterior midcingulate cortex on drinking behavior during thirst and following satiation. Proc. Natl. Acad. Sci. U S A 115, 786-791. doi: 10.1073/pnas.1717646115

Saksida, L. M., Bussey, T. J., Buckmaster, C. A., and Murray, E. A. (2007). Impairment and facilitation of transverse patterning after lesions of the perirhinal cortex and hippocampus, respectively. Cereb. Cortex 17, 108-115. doi: $10.1093 /$ cercor/bhj128

Sallet, J., Mars, R. B., Noonan, M. P., Andersson, J. L., O’Reilly, J. X., Jbabdi, S., et al. (2011). Social network size affects neural circuits in macaques. Science 334, 697-700. doi: 10.1126/science.1210027

Sander, D., Grafman, J., and Zalla, T. (2003). The human amygdala: an evolved system for relevance detection. Rev. Neurosci. 14, 303-316. doi: 10.1515/revneuro.2003.14.4.303

Santos, S., Almeida, I., Oliveiros, B., and Castelo-Branco, M. (2016). The role of the amygdala in facial trustworthiness processing: a systematic review and meta-analyses of fMRI studies. PLoS One 11:e0167276. doi: 10.1371/journal. pone. 0167276

Saper, C. B. (2000). Pain as a visceral sensation. Prog. Brain Res. 122, 237-243. doi: 10.1016/s0079-6123(08)62142-1

Saper, C. B. (2002). The central autonomic nervous system: conscious visceral perception and autonomic pattern generation. Annu. Rev. Neurosci. 25, 433-469. doi: 10.1146/annurev.neuro.25.032502.111311

Sato, W., Kochiyama, T., Uono, S., Matsuda, K., Usui, K., Usui, N., et al. (2017a). Bidirectional electric communication between the inferior occipital gyrus and the amygdala during face processing. Hum. Brain Mapp. 38, 4511-4524. doi: $10.1002 / \mathrm{hbm} .23678$

Sato, W., Kochiyama, T., Uono, S., Yoshimura, S., Kubota, Y., Sawada, R., et al. (2017b). Reduced gray matter volume in the social brain network in adults with autism spectrum disorder. Front. Hum. Neurosci. 11:395. doi: 10.3389/fnhum. 2017.00395

Saygin, A. P. (2007). Superior temporal and premotor brain areas necessary for biological motion perception. Brain 130, 2452-2461. doi: 10.1093/brain/awm162

Schiff, H. C., Johansen, J. P., Hou, M., Bush, D. E. A., Smith, E. K., Klein, J. E., et al. (2017). B-adrenergic receptors regulate the acquisition and consolidation phases of aversive memory formation through distinct, temporally regulated signaling pathways. Neuropsychopharmacology 42, 895-903. doi: 10.1038/npp. 2016.238

Schmelz, M., and Call, J. (2016). The psychology of primate cooperation and competition: a call for realigning research agendas. Philos. Trans. R. Soc. Lond B Biol. Sci. 371:20150067. doi: 10.1098/rstb.2015.0067

Schomaker, J., Walper, D., Wittmann, B. C., and Einhäuser, W. (2017). Attention in natural scenes: affective-motivational factors guide gaze independently of visual salience. Vision Res. 133, 161-175. doi: 10.1016/j.visres.2017. 02.003

Schott, G. D. (2012). Pictures as a neurological tool: lessons from enhanced and emergent artistry in brain disease. Brain 135, 1947-1963. doi: 10.1093/brain/ awr314

Schreurs, J., Seelig, T., and Schulman, H. (1986). ß2-adrenergic receptors on peripheral nerves. J. Neurochem. 46, 294-296. doi: 10.1111/j.1471-4159.1986. tb12961.x 
Schumann, C. M., and Amaral, D. G. (2005). Stereological estimation of the number of neurons in the human amygdaloid complex. J. Comp. Neurol. 491, 320-329. doi: 10.1002/cne.20704

Schumann, C. M., and Amaral, D. G. (2006). Stereological analysis of amygdala neuron number in autism. J. Neurosci. 26, 7674-7679. doi: 10.1523/JNEUROSCI.1285-06.2006

Schumann, C. M., and Amaral, D. G. (2009). "The human amygdala in autism," in The Human Amygdala, eds P. J. Whalen and E. A. Phelps (New York, NY: Guilford Press), 362-381.

Schumann, C. M., Barnes, C. C., Lord, C., and Courchesne, E. (2009). Amygdala enlargement in toddlers with autism related to severity of social and communication impairments. Biol. Psychiatry 66, 942-949. doi: 10.1016/j. biopsych.2009.07.007

Schumann, C. M., Noctor, S. C., and Amaral, D. G. (2011). "Neuropathology of autism spectrum disorders: postmortem studies," in Autism Spectrum Disorders, eds D. G. Amaral, G. Dawson and D. H. Geschwind (New York, NY: Oxford University Press), 539-565.

Shepherd, G. M. (2006). Smell images and the flavour system in the human brain. Nature 444, 316-321. doi: 10.1038/nature05405

Shin, L. M., and Liberzon, I. (2010). The neurocircuitry of fear, stress, and anxiety disorders. Neuropsychopharmacology 35, 169-191. doi: 10.1038/npp. 2009.83

Shinohara, K., Watabe, A. M., Nagase, M., Okutsu, Y., Takahashi, Y., Kurihara, H., et al. (2017). Essential role of endogenous calcitonin gene-related peptide in pain-associated plasticity in the central amygdala. Eur. J. Neurosci. 46, 2149-2160. doi: 10.1111/ejn.13662

Simmons, D. R., Robertson, A. E., McKay, L. S., Toal, E., McAleer, P., and Pollick, F. E. (2009). Vision in autism spectrum disorders. Vision Res. 49, 2705-2739. doi: 10.1016/j.visres.2009.08.005

Simons, L. E., Moulton, E. A., Linnman, C., Carpino, E., Becerra, L., and Borsook, D. (2014). The human amygdala and pain: evidence from neuroimaging. Hum. Brain Mapp. 35, 527-538. doi: 10.1002/hbm. 22199

Small, D. M. (2010). Taste representation in the human amygdala. Brain Struct. Funct. 214, 551-561. doi: 10.1007/s00429-010-0266-9

Small, D. M.,Zatorre, R. J., Dagher, A., Evans, A. C., and Jones-Gotman, M. (2001). Changes in brain activity relating to eating chocolate: from pleasure to aversion. Brain 124, 1720-1733. doi: 10.1093/brain/124.9.1720

Smith, F. W., and Goodale, M. A. (2015). Decoding visual object categories in early somatosensory cortex. Cereb. Cortex 25, 1020-1031. doi: $10.1093 /$ cercor/bht292

Smith, C. D., Lori, N. F., Akbudak, E., Sorar, E., Gultepe, E., Shimony, J. S., et al. (2009). MRI diffusion tensor tracking of a new amygdalo-fusiform and hippocampo-fusiform pathway system in humans. J. Magn. Reson. Imaging 29, 1248-1261. doi: 10.1002/jmri.21692

Spunt, R. P., and Adolphs, R. (2017). A new look at domain specificity: insights from social neuroscience. Nat. Rev. Neurosci. 18, 559-567. doi: 10.1038/nrn. 2017.76

Stanfield, A. C., McIntosh, A. M., Spencer, M. D., Philip, R., Gaur, S., and Lawrie, S. M. (2008). Towards a neuroanatomy of autism: a systematic review and meta-analysis of structural magnetic resonance imaging studies. Eur. Psychiatry 23, 289-299. doi: 10.1016/j.eurpsy.2007.05.006

Stefanacci, L., and Amaral, D. G. (2000). Topographic organization of cortical inputs to the lateral nucleus of the macaque monkey amygdala: a retrograde tracing study. J. Comp. Neurol. 421, 52-79. doi: 10.1002/(sici)10969861(20000522)421:1<52::aid-cne4>3.0.co;2-o

Stefanacci, L., and Amaral, D. G. (2002). Some observations on cortical inputs to the macaque monkey amygdala: an anterograde tracing study. J. Comp. Neurol. 451, 301-323. doi: 10.1002/cne.10339

Stefanacci, L., Suzuki, W. A., and Amaral, D. G. (1996). Organization of connections between the amygdaloid complex and the perirhinal and parahippocampal cortices in macaque monkeys. J. Comp. Neurol. 375, 552-582. doi: 10.1002/(sici)1096-9861(19961125)375:4<552::aid-cne2>3.3.co;2-j

Sturm, V., Fricke, O., Bührle, C. P., Lenartz, D., Maarouf, M., Treuer, H., et al. (2013). DBS in the basolateral amygdala improves symptoms of autism and related self-injurious behavior: a case report and hypothesis on the pathogenesis of the disorder. Front. Hum. Neurosci. 6:341. doi: 10.3389/fnhum. 2012.00341
Suzuki, W. A. (1996). Neuroanatomy of the monkey entorhinal, perirhinal and parahippocampal cortices: organization of cortical inputs and interconnections with amygdala and striatum. Semin. Neurosci. 8, 3-12. doi: 10.1006/smns.19 96.0002

Suzuki, W. A., and Amaral, D. G. (1994). Perirhinal and parahippocampal cortices of the macaque monkey: cortical afferents. J. Comp. Neurol. 350, 497-533. doi: 10.1002/cne.903500402

Tas, A., Yagiz, R., Tas, M., Esme, M., Uzun, C., and Karasalihoglu, A. R. (2007). Evaluation of hearing in children with autism by using TEOAE and ABR. Autism 11, 73-79. doi: 10.1177/1362361307070908

Taylor, K. I., Moss, H. E., Stamatakis, E. A., and Tyler, L. K. (2006). Binding crossmodal object features in perirhinal cortex. Proc. Natl. Acad. Sci. U S A 103, 8239-8244. doi: 10.1073/pnas.0509704103

Taylor, K. I., Moss, H. E., and Tyler, L. K. (2007). "The conceptual structure account: a cognitive model of semantic memory and its neural instantiation," in Neural Basis of Semantic Memory, eds J. Hart and M. A. Kraut (New York, NY: Cambridge University Press), 265-301.

Taylor, K. I., Stamatakis, E. A., and Tyler, L. K. (2009). Crossmodal integration of object features: voxel-based correlations in brain-damaged patients. Brain 132, 671-683. doi: 10.1093/brain/awn361

Tharpe, A. M., Bess, F. H., Sladen, D. P., Schissel, H., Couch, S., and Schery, T. (2006). Auditory characteristics of children with autism. Ear Hear. 27, 430-441. doi: 10.1097/01.aud.0000224981.60575.d8

Thomas-Anterion, C., Creac'h, C., Dionet, E., Borg, C., Extier, C., Faillenot, I., et al. (2010). De novo artistic activity following insular-SII ischemia. Pain 150, 121-127. doi: 10.1016/j.pain.2010.04.010

Toscano, J. E., Bauman, M. D., Mason, W. A., and Amaral, D. G. (2009). Interest in infants by female rhesus monkeys with neonatal lesions of the amygdala or hippocampus. Neuroscience 162, 881-891. doi: 10.1016/j.neuroscience.2009. 05.056

Tyler, L. K., Stamatakis, E. A., Bright, P., Acres, K., Abdallah, S., Rodd, J. M., et al. (2004). Processing objects at different levels of specificity. J. Cogn. Neurosci. 16, 351-362. doi: 10.1162/089892904322926692

Van Bavel, J. J., Packer, D. J., and Cunningham, W. A. (2008). The neural substrates of in-group bias: a functional magnetic resonance imaging investigation. Psychol. Sci. 19, 1131-1139. doi: 10.1111/j.1467-9280.2008. 02214.x

Van Bavel, J. J., Packer, D. J., and Cunningham, W. A. (2011). Modulation of the fusiform face area following minimal exposure to motivationally relevant faces: evidence of in-group enhancement (not out-group disregard). J. Cogn. Neurosci. 23, 3343-3354. doi: 10.1162/jocn_a_00016

Varela, F. J., Thompson, E., and Rosch, E. (1991). The Embodied Mind: Cognitive Science and Human Experience. Cambridge, MA: MIT Press.

Veinante, P., Yalcin, I., and Barrot, M. (2013). The amygdala between sensation and affect: a role in pain. J. Mol. Psychiatry 1:9. doi: 10.1186/2049-9256-1-9

Via, E., Radua, J., Cardoner, N., Happé, F., and Mataix-Cols, D. (2011). Metaanalysis of gray matter abnormalities in autism spectrum disorder. Arch. Gen. Psychiatry 68, 409-418. doi: 10.1001/archgenpsychiatry.2011.27

Vogt, B. A. (2009). "Regions and subregions of the cingulate cortex," in Cingulate Neurobiology and Disease, ed. B. A. Vogt (New York, NY: Oxford University Press), 3-30.

von Bonin, G., and Bailey, P. (1947). The Neocortex of Macaca mulatta. Urbana, IL: University of Illinois Press.

Von Der Heide, R., Vyas, G., and Olson, I. R. (2014). The social network-network: size is predicted by brain structure and function in the amygdala and paralimbic regions. Soc. Cogn. Affect. Neurosci. 9, 1962-1972. doi: 10.1093/scan/ nsu009

von Leupoldt, A., Sommer, T., Kegat, S., Baumann, H. J., Klose, H., Dahme, B., et al. (2009). Dyspnea and pain share emotion-related brain network. Neuroimage 48, 200-206. doi: 10.1016/j.neuroimage.2009.06.015

Vuilleumier, P. (2015). Affective and motivational control of vision. Curr. Opin. Neurol. 28, 29-35. doi: 10.1097/wco.0000000000000159

Vuilleumier, P., Richardson, M. P., Armony, J. L., Driver, J., and Dolan, R. J. (2004). Distant influences of amygdala lesion on visual cortical activation during emotional face processing. Nat. Neurosci. 7, 1271-1278. doi: $10.1038 / \mathrm{nn} 1341$

Wang, S., Jiang, M., Duchesne, X. M., Laugeson, E. A., Kennedy, D. P., and Adolphs, R. (2015). Atypical visual saliency in autism spectrum 
disorder quantified through model-based eye tracking. Neuron 88, 604-616. doi: 10.1016/j.neuron.2015.09.042

Wang, S., Tudusciuc, O., Mamelak, A. N., Ross, I. B., Adolphs, R., and Rutishauser, U. (2014). Neurons in the human amygdala selective for perceived emotion. Proc. Natl. Acad. Sci. U S A 111, E3110-E3119. doi: 10.1073/pnas. 1323342111

Watanabe, N., and Yamamoto, M. (2015). Neural mechanisms of social dominance. Front. Neurosci. 9:154. doi: 10.3389/fnins.2015.00154

Wegiel, J., Flory, M., Kuchna, I., Nowicki, K., Ma, S. Y., Imaki, H., et al. (2014). Stereological study of the neuronal number and volume of 38 brain subdivisions of subjects diagnosed with autism reveals significant alterations restricted to the striatum, amygdala and cerebellum. Acta Neuropathol. Commun. 2:141. doi: 10.1186/s40478-014-0141-7

Weigelt, S., Koldewyn, K., and Kanwisher, N. (2012). Face identity recognition in autism spectrum disorders: a review of behavioral studies. Neurosci. Biobehav. Rev. 36, 1060-1084. doi: 10.1016/j.neubiorev.2011.12.008

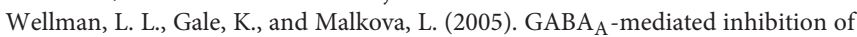
basolateral amygdala blocks reward devaluation in macaques. J. Neurosci. 25, 4577-4586. doi: 10.1523/jneurosci.2257-04.2005

Weston, C. S. E. (2012). Another major function of the anterior cingulate cortex: the representation of requirements. Neurosci. Biobehav. Rev. 36, 90-110. doi: 10.1016/j.neubiorev.2011.04.014

Weston, C. S. E. (2014). Posttraumatic stress disorder: a theoretical model of the hyperarousal subtype. Front. Psychiatry 5:37. doi: 10.3389/fpsyt.2014.00037

Whitehouse, A. J. O., and Bishop, D. V. M. (2008). Do children with autism 'switch off to speech sounds? An investigation using event-related potentials. Dev. Sci. 11, 516-524. doi: 10.1111/j.1467-7687.2008.00697.x

Williams, D. (1996). Autism: An Inside-Out Approach. London: Jessica Kingsley Publishers.

Wing, L. (1976). "Diagnosis, clinical description and prognosis," in Early Childhood Autism: Clinical, Educational and Social Aspects, ed. L. Wing 2nd Edn. (Oxford: Pergamon Press), 15-64.
Wright, P. H. (1985). "The acquaintance description form," in Understanding Personal Relationships: An Interdisciplinary Approach, eds S. Duck and D. Perlman (London: Sage Publications), 39-62.

Young, M. P., Scannell, J. W., Burns, G. A. P. C., and Blakemore, C. (1994). Analysis of connectivity: neural systems in the cerebral cortex. Rev. Neurosci. 5, 227-250. doi: 10.1515/revneuro.1994.5.3.227

Yukie, M. (2002). Connections between the amygdala and auditory cortical areas in the macaque monkey. Neurosci. Res. 42, 219-229. doi: 10.1016/s0168 0102(01)00325-x

Zangemeister, L., Grabenhorst, F., and Schultz, W. (2016). Neural basis for economic saving strategies in human amygdala-prefrontal reward circuits. Curr. Biol. 26, 3004-3013. doi: 10.1016/j.cub.2016.09.016

Zerubavel, N., Bearman, P. S., Weber, J., and Ochsner, K. N. (2015). Neural mechanisms tracking popularity in real-world social networks. Proc. Natl. Acad. Sci. U S A 112, 15072-15077. doi: 10.1073/pnas.15114 77112

Ziemann, A. E., Allen, J. E., Dahdaleh, N. S., Drebot, I. I., Coryell, M. W., Wunsch, A. M., et al. (2009). The amygdala is a chemosensor that detects carbon dioxide and acidosis to elicit fear behavior. Cell 139, 1012-1021. doi: 10.1016/j.cell.2009.10.029

Conflict of Interest Statement: The author declares that the research was conducted in the absence of any commercial or financial relationships that could be construed as a potential conflict of interest.

Copyright (c) 2018 Weston. This is an open-access article distributed under the terms of the Creative Commons Attribution License (CC BY). The use, distribution or reproduction in other forums is permitted, provided the original author(s) and the copyright owner(s) are credited and that the original publication in this journal is cited, in accordance with accepted academic practice. No use, distribution or reproduction is permitted which does not comply with these terms. 